\title{
Stratospheric geoengineering impacts on EI Niño/Southern Oscillation
}

\author{
C. J. Gabriel and A. Robock \\ Department of Environmental Sciences, Rutgers University, New Brunswick, NJ, USA \\ Correspondence to: C. J. Gabriel (cjgabriel7@gmail.com)
}

Received: 2 March 2015 - Published in Atmos. Chem. Phys. Discuss.: 27 March 2015

Revised: 17 October 2015 - Accepted: 20 October 2015 - Published: 27 October 2015

\begin{abstract}
To examine the impact of proposed stratospheric geoengineering schemes on the amplitude and frequency of El Niño/Southern Oscillation (ENSO) variations we examine climate model simulations from the Geoengineering Model Intercomparison Project (GeoMIP) G1-G4 experiments. Here we compare tropical Pacific behavior under anthropogenic global warming (AGW) using several scenarios: an instantaneous quadrupling of the atmosphere's $\mathrm{CO}_{2}$ concentration, a $1 \%$ annual increase in $\mathrm{CO}_{2}$ concentration, and the representative concentration pathway resulting in $4.5 \mathrm{~W} \mathrm{~m}^{-2}$ radiative forcing at the end of the 21 st century, the Representative Concentration Pathway 4.5 scenario, with that under G1-G4 and under historical model simulations. Climate models under AGW project relatively uniform warming across the tropical Pacific over the next several decades. We find no statistically significant change in ENSO frequency or amplitude under stratospheric geoengineering as compared with those that would occur under ongoing AGW, although the relative brevity of the G1-G4 simulations may have limited detectability of such changes. We also find that the amplitude and frequency of ENSO events do not vary significantly under either AGW scenarios or G1G4 from the variability found within historical simulations or observations going back to the mid-19th century. Finally, while warming of the Niño3.4 region in the tropical Pacific is fully offset in G1 and G2 during the 40-year simulations, the region continues to warm significantly in G3 and G4, which both start from a present-day climate.
\end{abstract}

\section{Introduction}

\subsection{Background}

The warming of Earth in the Industrial Age is unequivocal, and it is extremely likely that the warming since 1950 is primarily the result of anthropogenic emission of heat trapping gases rather than natural climate variability (IPCC, 2013). Ice core records from the European Project for Ice Coring in Antarctica reveal that current concentrations of the heat trapping gases carbon dioxide and methane are higher now than at any time during the past 650000 years (Siegenthaler et al., 2005). All realistic emissions scenarios utilized in the Intergovernmental Panel on Climate Change Fifth Assessment Report reveal that the modeled global mean temperature in 2100 will exceed the full distribution of global mean temperature in proxy reconstructions of global temperature over the past 11300 years of the Holocene (Marcott et al., 2013). Ongoing warming is unprecedented in human history both in magnitude and rate of change.

The realization that weathering the impacts of this warming may be beyond human adaptive capacity has generated many proposed mitigation techniques, which focus on limiting emission or increasing storage of heat-trapping gases such as carbon dioxide. Implementation costs and economic, political and societal factors limit societies' will and ability to impose mitigation measures. This has forced a recent consideration of geoengineering: intentional manipulation of global-scale physical processes (Crutzen, 2006). Specifically, a form of solar radiation management (SRM) known as stratospheric geoengineering has been proposed. Continuous sulfate injections into the tropical stratosphere have the potential to create a long-lasting, well-mixed sulfate aerosol layer, which could reduce incoming shortwave radi- 
ation, in an attempt to offset the warming by the excess heattrapping gases (Robock, 2008). The cost of implementing stratospheric geoengineering is most likely not prohibitive (Robock et al., 2009). Any decision about the implementation would likely be based on substantive issues of risk and feasibility of governance (Caldeira et al., 2013).

Assessment of the efficacy and risk profile of stratospheric geoengineering is underway in a series of standardized climate modeling experiments as part of the Geoengineering Model Intercomparison Project (GeoMIP) (Kravitz et al., 2011). Any assessment of the impact of geoengineering on climate must include analysis of how geoengineering could alter patterns of natural climate variability and how geoengineering could change the mean climate state in such a way that natural climate variability would evolve differently in an intentionally forced world.

\subsection{Research question and motivation}

Here we seek to examine whether stratospheric geoengineering would have any impact on the frequency or amplitude of El Niño/Southern Oscillation (ENSO). More specifically, will ENSO amplitude and frequency be different under a regime of geoengineering from that in a global warming scenario? In addition to an exploration of changes in ENSO frequency and amplitude under different scenarios, we seek to determine how sea surface temperatures (SSTs) in the tropical Pacific will evolve under geoengineering relative to historical and global warming scenarios over the entire length of the simulations.

ENSO is the most important source of interannual climate variability. Its amplitude, frequency and the attendant teleconnection patterns have critical consequences for global climate patterns (McPhaden, 2006). ENSO exhibits a 2-7-year periodicity with warm (El Niño) and cold (La Niña) events, each lasting 9-12 months and peaking during the DJF season.

The possibility of a connection between warm ENSO events subsequent to stratospheric aerosol loading via volcanism has been explored in both proxy records and model simulations. Despite its relative simplicity, the Zebiak-Cane (ZC) model (Zebiak and Cane, 1987) possesses an exceptional ability to describe the coupled ocean-atmosphere dynamics of the tropical Pacific. By forcing ZC with the calculated radiative forcing from each eruption in the past 1000 years, Emile-Geay et al. (2007) showed that El Niño events tend to occur in the year subsequent to major tropical eruptions, including Tambora (1815) and Krakatau (1883). A strong enough cooling by a volcanic event is likely to cause warming in the eastern Pacific over the next 1 to 2 years (Mann et al., 2005). The dynamical "ocean thermostat" describes the mechanism underlying differential heating in the eastern and western Pacific. In the presence of a global strong negative radiative forcing, the western Pacific will cool more quickly than the eastern Pacific. This is because the western
Pacific mixed layer's heat budget is almost exclusively from solar heating, while, in the east, both horizontal divergence and strong upwelling contributes to the mixed layer heat budget. Therefore, a uniform solar dimming is likely to result in a muted zonal SST gradient across the equatorial tropical Pacific (Clement et al., 1996). A diminished SST gradient promotes a weakening of trade winds, resulting in less upwelling and an elevated thermocline, further weakening the crossbasin SST gradient. This "Bjerknes feedback" describes how muting of the SST gradient brought on by negative radiative forcing alone is exacerbated by ocean-atmosphere coupling (Bjerknes, 1969). Following the initial increase in El Niño likelihood, La Niña event probability peaks in the third year post-eruption (Maher et al., 2015).

Trenberth et al. (1997) placed the likelihood of an ENSO event in a given year at $31 \%$. Using $200 \mathrm{ZC}$ simulations lasting 1000 years each, Emile-Geay et al. (2007) showed that the probability of an El Niño event in the year after the simulated volcanic forcing never exceeded $43 \%$ absent negative (volcanic) radiative forcing of greater than $1 \mathrm{~W} \mathrm{~m}^{-2}$, with modeled next-year El Niño probabilities clustered around $31 \%$. Volcanic events with radiative forcing ranging from -1 to $-3.3 \mathrm{~W} \mathrm{~m}^{-2}$ fit into a transition regime, with the number of events approaching or exceeding the $43 \%$ probability maximum. For all modeled volcanic events with radiative forcing exceeding $-3.3 \mathrm{~W} \mathrm{~m}^{-2}$, the probability of a nextyear El Niño exceeded $43 \%$. This is a forced regime - negative radiative forcing applied to the $\mathrm{ZC}$ model forced $\mathrm{El}$ Niño likelihood out of a free regime and into a regime where enhanced variability would be more likely (Emile-Geay et al., 2007). In the transition and forced regimes, increased El Niño amplitude is also simulated following moderate to strong volcanic events.

Geoengineering schemes simulated in current general circulation models (GCMs) introduce long-lasting radiative forcing of the magnitude found in the transition regime. This means that while radiative forcing of that magnitude does not force the probability of a next-year El Niño event to exceed the $43 \%$ free oscillation maximum threshold, the radiative forcing applied does fit into a range in which the $43 \%$ threshold is exceeded during the next year in some simulations. Therefore, we ask whether solar dimming lasting many years, as a proxy for sulfate injections, or sulfate injections lasting many years as simulated by models may also alter El Niño or La Niña event frequency and amplitude. Rather than using the $\mathrm{ZC}$ model, we use various geoengineering experiment designs in modern, state-of-the-art GCMs to determine whether forcing from stratospheric aerosol injections, added continuously, will load the deck in favor of El Niño events in the succeeding year. No modeling study has ever evaluated the impact of long-term solar dimming or continuous stratospheric sulfate injections on ENSO. Additionally, little work has been done to assess the oceanic response to SRM.

Since our comparison is between El Niño and La Niña amplitude and frequency under a geoengineering regime and un- 
der a scenario of unabated global warming, the evolution of ENSO behavior under global warming, independent of geoengineering, is also of interest. Overwhelming evidence from climate model experiments shows that geoengineering could effectively reduce or offset the surface temperature increase resulting from global warming by limiting the amount of incoming shortwave radiation, compensating for global warming (Jones et al., 2010; Robock et al., 2008). An alternative theory for why ENSO amplitude and frequency may be different in the future under a geoengineering regime than under global warming is based on the fact that ENSO events may evolve differently from a warmer tropical Pacific mean state under global warming than if a geoengineering scheme were imposed.

Kirtman and Schopf (1998) showed that tropical Pacific mean-state changes on decadal timescales are more responsible than atmospheric noise for changes in ENSO frequency and predictability. This does not imply any external cause for the changes in ENSO but does imply that a uniform warming of the tropical Pacific may cause changes in ENSO. Despite the lack of a robust multi-model ENSO signal in the Coupled Model Intercomparison Project 5 (CMIP5) models (Taylor et al., 2012), there are suggestions that strong El Niño events may become far more likely under global warming, specifically in a multi-model ensemble experiment using the Representative Concentration Pathway 8.5 (RCP8.5) scenario (Meinshausen et al., 2011). As global warming continues, background state tropical Pacific SSTs are expected to warm faster along the Equator than off the Equator, and faster in the east than in the west - the inverse of the ocean dynamical thermostat mechanism (Held et al., 2010). With the weaker zonal SST gradient in the tropical Pacific, there will be more occurrences of higher SSTs in the eastern Pacific, promoting large-scale organization of convection further to the east, with twice as many strong El Niño events over 200 years of RCP8.5 runs (Cai et al., 2014). We will not seek to replicate the RCP8.5 results. No physically plausible geoengineering experiment would seriously attempt to offset RCP8.5 with solar dimming or sulfate injections. Therefore, we use RCP4.5 as the control in GeoMIP experiments and will attempt to identify if the long-term mean state changes generate divergent ENSO frequency under geoengineering and global warming.

\subsection{Representation of the Tropical Pacific in CMIP}

The ability to detect subtle differences in the tropical Pacific under global warming vs. geoengineering requires sufficiently skilled models. Proper depiction of ENSO in a GCM is confounded by the fact that ENSO is a coupled oceanatmospheric phenomenon generated by the interaction of many processes, each occurring on one of several different timescales. Nearly all CMIP3 models were able to produce an ENSO cycle, but significant errors were evident (Guilyardi et al., 2009). Analysis of CMIP5 models has shown sig- nificant improvement, but the improvement has not been revolutionary. Such a comparison is facilitated by standardized "metrics developed within the CLIVAR (Climate and Ocean: Variability, Predictability and Change) Pacific Panel that assess the tropical Pacific mean state and interannual variability" (Bellenger et al., 2013). The following metrics were used in the CLIVAR CMIP3/CMIP5 comparison: ENSO amplitude, structure, spectrum and seasonality. Some processbased variables were also studied, including the Bjerknes feedback.

Key results included that $65 \%$ of CMIP5 models produce ENSO amplitude within $25 \%$ of observations as compared to $50 \%$ for CMIP3. Other results included improved seasonal phase-locking and the proper spatial pattern of SSTs at the peak of ENSO events. Despite the improvement in these result-based variables, analysis of process-based variables, such as the Bjerknes feedback, showed less consistent improvement. This gives rise to the possibility that the bottomline improvement in ENSO depiction was at least partially the result of error cancellation rather than clear improvements in parameterization and simulation of physical processes (Yeh et al., 2012; Guilyardi et al., 2012; Bellenger et al., 2013). A particularly striking area of divergence between modeling and observations is in the absence of a shift from a subsidence regime to a convective regime in the equatorial central Pacific during evolution of El Niño events. Many models maintained a subsidence regime or convective regime at all times over the equatorial central Pacific (Bellenger et al., 2013). This error likely led to the muting of the negative shortwave feedback in many models, leading to muted damping of ENSO events in those models.

Both the improvement in depiction of ENSO amplitude and seasonality from CMIP3 to CMIP5 and the ability to understand the simulation of key process-based variables motivate an analysis of ENSO and geoengineering using CMIP5 GCMs.

It is difficult to draw robust conclusions about future ENSO variability. There is no unambiguous signal of how ENSO may change under global warming in CMIP5. However, several recent studies have been able to detect statistically significant changes in ENSO. For example, Cai et al. (2015) shows a statistically significant increase in the frequency of extreme La Niña events under RCP8.5 as compared to a control scenario. They selected 21 of 32 available CMIP5 models because of their ability to accurately simulate processes associated with extreme ENSO events. Each model simulation lasted for a period of 200 years.

The detectability of changes in ENSO variability in future SRM modeling experiments will likely be buoyed by the availability of more models and longer simulations. Additionally, future SRM experiments that attempt to offset or partially offset more extreme anthropogenic global warming (AGW) scenarios, such as RCP6.0 and RCP8.5, may improve detectability. Given that detecting an ENSO change in a 200-year record with 21 different participating GCMs is 

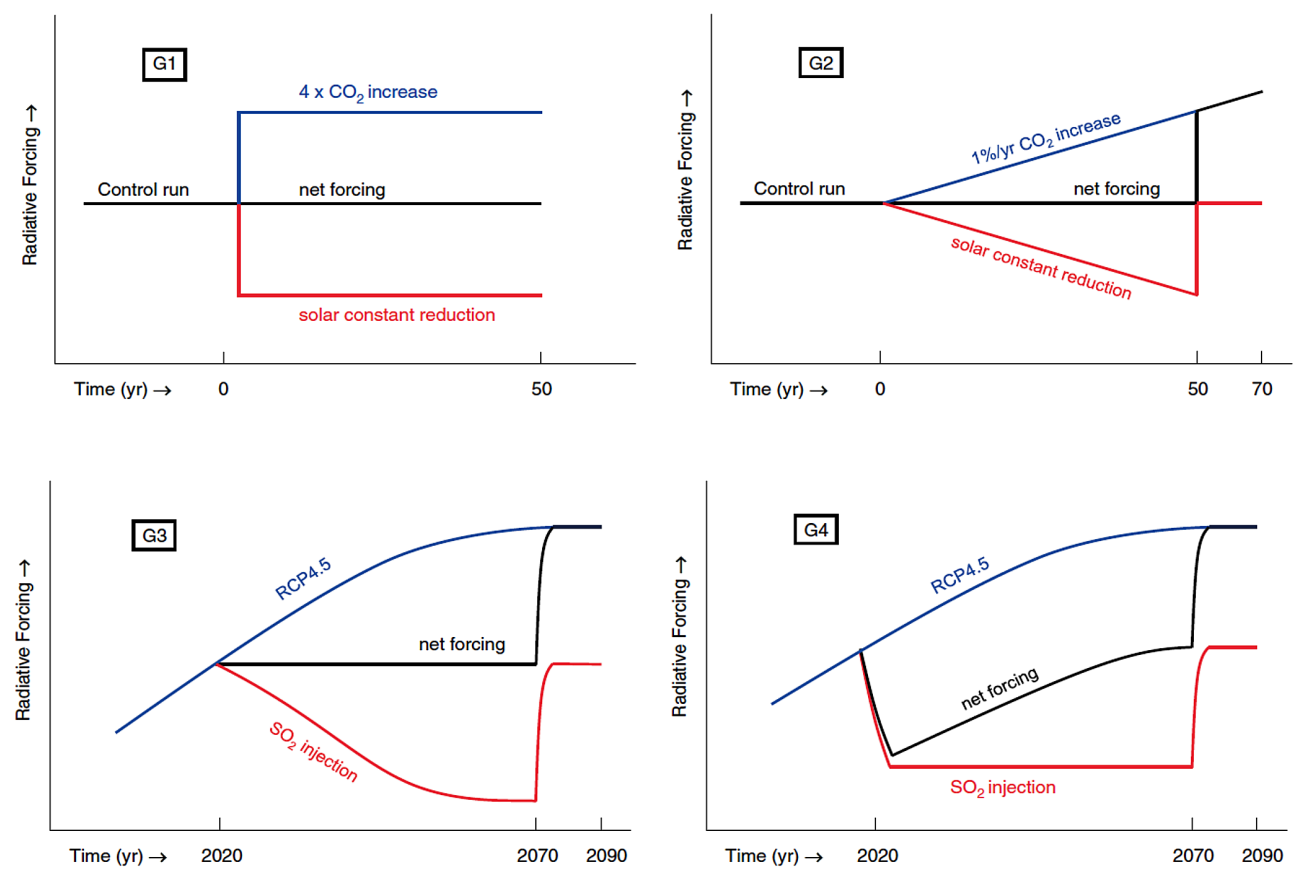

Figure 1. GeoMIP G1-G4 experiment designs. Figures 1-4 from Kravitz et al. (2011).

not straightforward, we anticipate that detecting changes in ENSO by analyzing GeoMIP may be difficult. Further, we recognize that even if significant differences between ENSO in a geoengineered world as opposed to an AGW world are evident, a large number of comparisons will have to be made, and further analysis of significant results will need to be performed to determine whether or not the result is robust. Despite these substantial caveats, it would be irresponsible for geoengineering research to progress without consideration of how a geoengineering regime could alter ENSO.

\section{Methods}

We begin with the simple question of whether or not, in a single GeoMIP participating model that simulates ENSO well, a difference in ENSO amplitude or frequency is evident in a comparison between one experiment and its control. Unsurprisingly, given the large inherent variability in ENSO, such a change is not detectable in one model. Given that, we adopt an approach in which we use output from nine GeoMIP-participating GCMs, each running between one and three ensemble members of each experiment G1G4. The simulations are then analyzed. These GeoMIP experiments are described by Kravitz et al. (2011). See Fig. 1 for schematics of GeoMIP experiments G1-G4 and Tables 1 and 2 for details about the GCMs used in these experiments. The G1 experiment - instantaneous quadrupling of $\mathrm{CO}_{2} \mathrm{cou}-$ pled with a concurrent fully offsetting reduction of the solar constant - was designed to elicit robust responses, which then facilitate elucidation of physical mechanisms for fur- ther analysis. We compared G1 output to a control run in which the atmospheric carbon dioxide concentration is instantaneously quadrupled. The G2 experiment combines a $1 \% \mathrm{yr}^{-1} \mathrm{CO}_{2}$ increase with a fully offsetting reduction in the solar constant. The G3 experiment combines RCP4.5 with a fully offsetting sulfur dioxide injection. The G4 experiment - stratospheric loading of $25 \%$ the $\mathrm{SO}_{2}$ mass of the 1991 Mt. Pinatubo volcanic eruption $(5 \mathrm{Tg})$ each year concurrent with RCP4.5, with top-of-atmosphere radiation balance not fixed at $0-$ attempts to replicate a physically and politically plausible large-scale geoengineering deployment scenario.

Each experiment (G1-G4) is compared to its respective control scenario: $4 \mathrm{XCO}_{2}$ for $\mathrm{G} 1,1 \%$ annual $\mathrm{CO}_{2}$ increase for $\mathrm{G} 2$ and RCP4.5 for G3 and G4. We compare the means of each sample by applying a two-independent-sample $t$ test assuming unequal variance. To apply this test, the populations making up the two samples being compared must both follow a normal distribution and the two populations must be measured on an equal-interval scale. In our case, we must establish normality to move forward to performing a valid $t$ test. If the samples were a bit larger $(n>30$, where $n$ is the size of the sample), the central limit theorem would likely make analysis of the normality of the respective samples moot.

There are many ways to assess normality. An important, but partially qualitative, first step in determining whether a sample is normally distributed is to create a histogram of values for each sample. This was done for each sample and the distribution appeared roughly normal.

Skewness and kurtosis are the properties of a distribution that serve as the basis for calculation of the widely used 
Table 1. The names of the climate models used in this study, with short names and references. Asterisks indicate that the models were excluded from comparison due to unrealistic ENSO variability.

\begin{tabular}{lll}
\hline Model & Model short name & Reference \\
\hline BNU-ESM* & BNU & Dai et al. (2003) \\
CanESM2 & CanESM & Arora et al. (2011) \\
CSIRO-Mk3L & CSIRO & Phipps et al. (2011, 2012) \\
GISS-E2-R & GISS & Schmidt et al. (2006) \\
HadGEM2-ES & HadGEM & Collins et al. (2011) \\
IPSL-CM5A-LR & IPSL & Dufresne et al. (2013) \\
MIROC-ESM* & MIROC & Watanabe et al. (2011) \\
MIROC-ESM-CHEM* & MIROC-C & Watanabe et al. (2011) \\
MPI-ESM-LR & MPI & Giorgetta et al. (2013) \\
\hline
\end{tabular}

Table 2. Models analyzed in each experiment. Asterisks indicate that the models were excluded from comparison due to unrealistic ENSO variability. The number of ensemble members for each experiment is given in parentheses after the model name.

\begin{tabular}{ll}
\hline a. Models in G1 & b. Models in G2 \\
\hline BNU-ESM* (2) & BNU-ESM* (3) \\
CanESM2 (3) & CanESM2 (3) \\
CSIRO-Mk3L (3) & CSIRO-Mk3L (3) \\
GISS-E2- (3) & GISS-E2-R] (3) \\
HadGEM2-ES (1) & HadGEM2-ES (3) \\
IPSL-CM5A-LR (1) & IPSL-CM5A-LR (1) \\
MIROC-ESM* (1) & MIROC-ESM* (1) \\
MPI-ESM-LR (1) & MPI-ESM-LR (1) \\
\hline c. Models in G3 & d. Models in G4 \\
\hline BNU-ESM* (1) & BNU-ESM* (2) \\
GISS-E2-R (3) & CanESM2 (3) \\
HadGEM2-ES (2) & CSIRO-Mk3L (3) \\
IPSL-CM5A-LR (1) & GISS-E2-R (3) \\
MPI-ESM-LR (3) & HadGEM2-ES (1) \\
& IPSL-CM5A-LR (1) \\
& MIROC-ESM* (1) \\
& MIROC-ESM-CHEM* (1) \\
& MPI-ESM-LR (1) \\
\hline
\end{tabular}

formal D'Agostino's $K^{2}$ test for goodness of fit. Conceptually, the $K^{2}$ test concurrently examines whether a sample is skewed (to the left or right) or peaked (or squished) relative to a normal distribution (D'Agostino, 1990). Skewness is a measure of symmetry around the sample mean, while kurtosis assesses whether a distribution is sharply peaked or flattened relative to a normal distribution (DeCarlo, 1997). A perfect normal distribution has a skewness value of 0 and kurtosis value of 3 . The kurtosis value of 3 for a normal distribution is equivalent to an excess kurtosis value of 0 .

Skewness values of less than twice that of $(6 / n)^{0.5}$ are consistent with a symmetric distribution. Kurtosis values of less than twice that of $(24 / n)^{0.5}$ are consistent with a normal distribution. No metric evaluated in the experiments showed either skewness or kurtosis values exceeding the limits of what is consistent with a normal distribution. Based on this analysis, we are comfortable proceeding with the use of a two-independent-sample $t$ test. We are forced to assume unequal variance due to somewhat different variances within the samples being compared. We choose to use $90 \%$ confidence intervals to enhance detectability. However, by narrowing the confidence intervals, we are forced to supplement the finding of a significant result by either subsequently applying a bootstrapping method for an original finding pertinent to geoengineering and AGW or to consult the appropriate studies to establish the veracity of a significant finding that matches the findings in other work, such as in a comparison between control or historical runs.

Even with carefully applied methods for analysis, detection of changes in future ENSO variability under different scenarios is challenging. As we are limited in both the length and number of geoengineering simulations, we aggregate geoengineering experiments, when appropriate, to increase sample size. We combine experiments only when the aggregated experiments form a group that is neatly distinct from its matching comparison group. Aggregated experiments must simulate a future climate that both starts from a similar mean climate and follows a similar trend, or lack of a trend, throughout the experimental period. After applying this standard, we are able to aggregate G1 and G2, since the experiments both initialize from a preindustrial climate and the anthropogenic warming imposed is fully offset by the solar dimming. We are also able to aggregate G3 and G4, since both initialize from a year 2020 climate and follow trajectories in which RCP4.5 is either fully (G3) or largely (G4) offset by constant sulfur dioxide injections during the experimental period. Application of this standard for aggregation of experiments precludes the aggregation of all GeoMIP experiments G1-G4 into a single ensemble, as the experiments initialize from different climates and follow independent trajectories thereafter. This standard is also applied when we consider aggregating control experiments. Since each control experiment - instantaneous quadrupling of $\mathrm{CO}_{2}, 1 \% \mathrm{yr}^{-1}$ $\mathrm{CO}_{2}$ increase runs and RCP4.5 - depicts climates that are 
distinct from each other, no aggregation of control experiments is performed.

To identify and analyze ENSO variability and amplitude, absent of the contamination of the signal induced in the immediate aftermath of application of initial solar dimming or stratospheric aerosol forcing, the first 10 years of each geoengineering model run were removed. The relevant comparison periods become either "years 11-50" in G1 and 20302069 in G2-G4. Initial forcing is applied in "year 1" in G1 and in 2020 in G2-G4. This 40-year interval is then compared to RCP4.5 2030-2069 and historical 1966-2005 for each respective model and to observations. We used the Kaplan et al. (1998) SST data set because it is well documented and used in many of the referenced papers. Differences between the Kaplan et al. (1998) data and other available data sets are trivial during the period of data used.

We used several SST-based indices to quantify the amplitude and phase of the ENSO cycle. For each ensemble member of each model, a time series of the Niño3.4 index was generated. We chose Niño3.4 over Niño3 or Niño4 because we find that the Niño3.4 region remains the center of action for ENSO variability both in observations and models. The Niño3.4 region is the area $120-170^{\circ} \mathrm{W}$ and $5^{\circ} \mathrm{N}-5^{\circ} \mathrm{S}$. The Niño3 region misses a good deal of the Modoki ENSOtype variability, while Niño4 misses a good deal of canonical ENSO-type variability. We define an ENSO event as a departure of the 5-month running mean Niño3.4 index (computed over $5^{\circ} \mathrm{S}-5^{\circ} \mathrm{N}, 120-170^{\circ} \mathrm{W}$ ) of greater than $0.5 \mathrm{~K}$ from the 2030-2069 climatology, with the linear trend removed from the 2030-2069 climatology before anomalies are calculated. Cold and warm events have the same definition just with opposite sign. Anomalies in the historical data and the observational record are calculated relative to a 1966-2005 climatology, which is also detrended before anomalies are calculated. G1 output is analyzed absent detrending, as there is no trend in the data. We used skin temperature $\left(T_{\mathrm{S}}\right)$ anomalies rather than SST anomalies to build the Niño3.4 time series for the BNU, IPSL and MPI and for models, because they were available on a regular grid. For the purpose of computing an anomaly based index, the variable $T_{\mathrm{S}}$ is an excellent SST proxy variable, which is interchangeable with SST.

Before we proceeded with the approach described above, concerns about the detectability of changes in ENSO variability during the period of modeled geoengineering compelled us to also consider non-SST-related measures of changes in the tropical Pacific. Might detectability of changes in ENSO be more evident from analyzing changes in non-SST-based ENSO indices? First, we considered the Southern Oscillation Index (SOI), which is a standardized index based on the atmospheric pressure difference between Darwin, Australia and Tahiti, because climate change does not produce SOI trends, except for a trivial increase as a result of increased water vapor concentration in a warmer world. Ideally, using SOI as a proxy for SST or $T_{\mathrm{S}}$ would allow inspection of the data absent the complications of dealing with a trend. Unfortunately SOI simulations show somewhat muted variability when compared with SST and $T_{\mathrm{S}}$-based indexes in the GCMs.

While the muted variability prevents the use of SOI as a proxy for the SST-based Niño3.4 index without redefining the requisite SOI thresholds for warm and cold ENSO events, we see that the ocean-atmosphere coupling, as reflected in the SOI, follows a realistic spatial structure. However, the spatial extent of the SST/SOI correlation is suppressed. Also, the magnitude of the correlation is realistic in the area that is the heart of ENSO variability. The area of prominent ENSO variability covers a smaller spatial area than that seen in observations, but the center of action is located in the same place as in observations. Additionally, the maximum values of the SST/SOI correlation in the historical models and the observations over the same period are both approximately the same $(r=0.8)$.

Figure 2 shows a spatial comparison between observed SOI/SST correlation and that modeled in a representative GISS historical run spanning the same time interval as the observations, and Fig. 3 for corresponding time series. These examples are representative of the other CMIP5 GCMs used in this study. Although the somewhat muted SOI variability prevented SOI analysis from being used in our study, the CMIP5 GeoMIP GCMs do produce plausible oceanatmosphere coupling, albeit not extending as far eastward or away from the Equator as seen in observations.

We also explored changes in zonal surface winds and the possibility of a detectable weakening trend in the Walker Circulation and its relationship with ENSO. Vecchi et al. (2006) identified a weakening of the ascending branch of the Walker circulation over equatorial southeast Asia. This change likely occurred as a result of increased precipitation. Precipitation increases much more slowly than humidity as a result of global warming. Therefore, the circulation weakens to maintain a balance of transport of water vapor out of the areas under the ascending branch that features extensive convection (Held and Soden 2006). These changes in the Walker Circulation were evident in the spatial pattern and trend of tropical Pacific sea level pressure (SLP) both in models that applied an anthropogenic change in radiative forcing over the historical period 1861-1990 and in the 21st century.

Unfortunately, considering changes in zonal wind and SLP is prevented by both the large inherent variability of SLP and zonal winds in the tropical Pacific and the difficulty in deconvoluting the possible Walker Circulation weakening and ENSO change signals. In the observational record, 30-50year changes in the Walker Circulation can occur concurrently with extended periods of more frequent ENSO warm events (Power and Smith, 2007). Hence, the observed weakening of the Walker Circulation during a period of somewhat more frequent ENSO warm events is not necessarily the result of a anthropogenically forced change in the Walker Circulation but is instead convoluted by increased ENSO warm events and other inherent variability in the Tropical 
GISS-E2-R historical correlation between 5 -month running mean SOI and SST, 1966-2005.

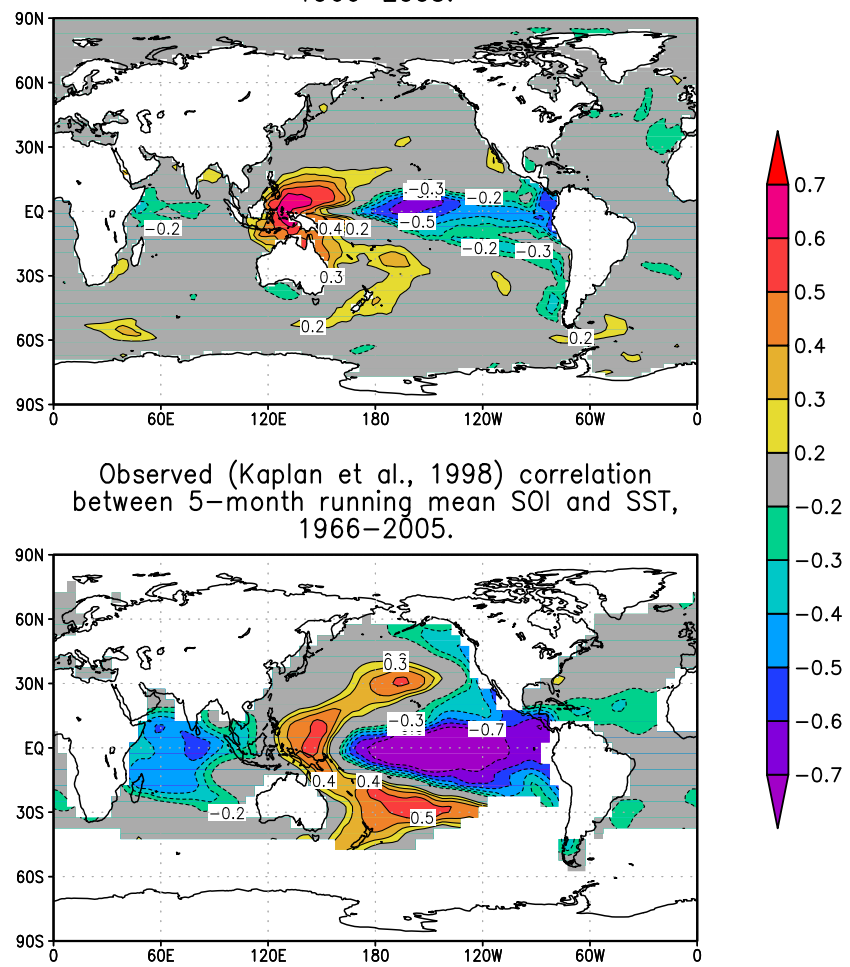

Figure 2. Top panel shows spatial correlation between GISS historical sea surface temperature (SST) and the Southern Oscillation Index (SOI). The area of strong negative correlation is confined to a small region in the central Pacific, relative to the broad area of strong negative correlation in the observations in the bottom panel, which shows the spatial correlation between NCEP SLP reanalysis and the Kaplan et al. (1998) SST observations data set.

Pacific. The period of time required to robustly detect and attribute changes in the tropical Pacific Walker Circulation is found to be up to 130 years (Vecchi et al., 2006; Vecchi and Soden, 2007) and no less than 60 years (Tokinaga et al., 2012). Because we cannot deconvolute the two signals in such a 40-year interval, we reject using zonal wind or SLP spatial pattern or trend as a proxy for ENSO. Additionally, as mentioned earlier, Cai et al. (2015) showed that a robust weakening of the Walker Circulation under RCP8.5 counterintuitively co-occurs with a period of anomalously strong La Niña events as a result of increased heating over the Maritime continent. Therefore, while changes in atmospheric Walker Circulation over the tropical Pacific can be impacted by ENSO on decadal timescales, the changes may also be entirely unrelated to ENSO variability.

Lastly, based on the mechanism underlying the ocean component of ENSO, we conjecture that changes in thermocline depth or upwelling strength in the eastern and central Pacific might constitute a helpful, non-SST-based indicator of changes in ENSO variability. However, given the some- what difficult time CMIP5 models have simulating ENSO, it would be preferable to not consider these metrics, since they cannot be evaluated in the models with a long observational record.

These endeavors to utilize a non-SST-based Niño3.4 index are now set aside due in large part to the robust observational record of SST and the noisy nature of atmospheric variables. Next, we turn to defining what will constitute an ENSO event in our experiments. Presently the National Oceanic and Atmospheric Administration Climate Prediction Center defines the climatological base period from which we calculate the departure from the current value and define an ENSO event as 1981-2010. We depart from this definition due to the robust warming trend in tropical SST in the Pacific both during the 1966-2005 comparison and in 2030-2069 model runs, which show continued warming of the tropical Pacific. The detrended 40-year average produces a more realistic assessment of the base climate from which a particular ENSO event would evolve. This avoids the trap of identifying spurious ENSO events toward the end of the time series, which are really artifacts of the warming trend. Ideally, a climatological period in a rapidly changing climate would span less than 40 years. However, longer-term natural trends in Pacific SST variability, including extended ENSO warm or cold periods, force use of a lengthy climatological base period to avoid comparing variability against a climatology that also includes that same variability.

The ENSO parameters evaluated are amplitude and frequency. El Niño amplitude is defined here as the peak anomaly value (in K) found during each El Niño event in the time series. La Niña amplitude is defined here as the mean negative peak anomaly value (in K) found during each ENSO event in the time series. Frequency is counted as the number of warm and cold events in each 40-year time slice. These parameters are chosen because ENSO frequency and amplitude have particular importance as global climate drivers.

The ENSO frequency and amplitude calculated in each ensemble member of each experiment (G1-G4) are compared (1) to other ensemble members from the same model for the same experiment, when available, (2) to their respective control runs, (3) to runs from other models with the same experimental design and (4) with different experimental designs, (5) to historical model runs and (6) to observations. From this we seek to identify significant differences between model output from geoengineering scenarios, global warming and historical runs compared to each other and to observations, as well as differences between models running the same G1G4 experiment. Not only do we seek to analyze differences in ENSO amplitude and frequency between different scenarios, but we also seek to identify ENSO tendencies specific to particular models. The discussion below includes the successes and limitations of CMIP5 GCMs in depicting ENSO.

In addition to seeking to identify changes in ENSO variability, we attempt to describe the evolution of Niño3.4 SSTs during a period of geoengineering as compared to AGW or 


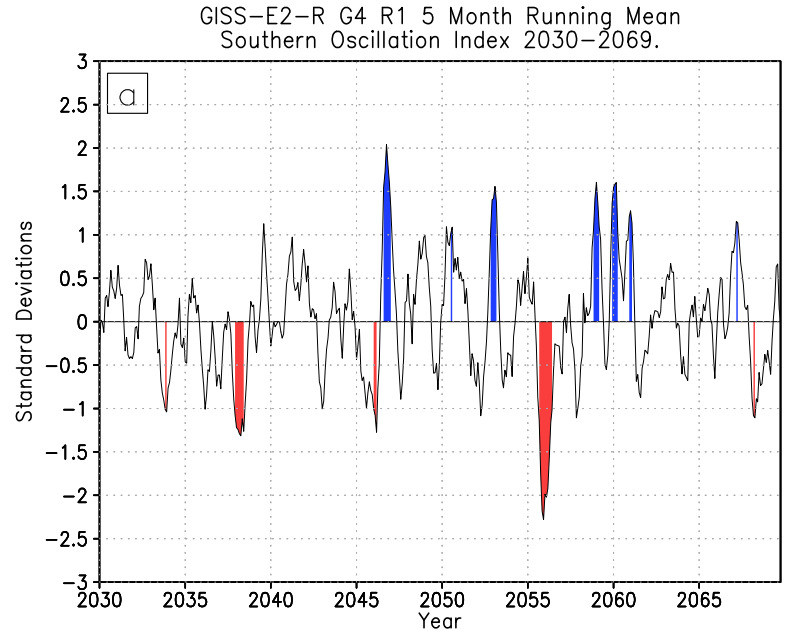

GISS G4 R1 5 Month Running Mean Nino 3.4

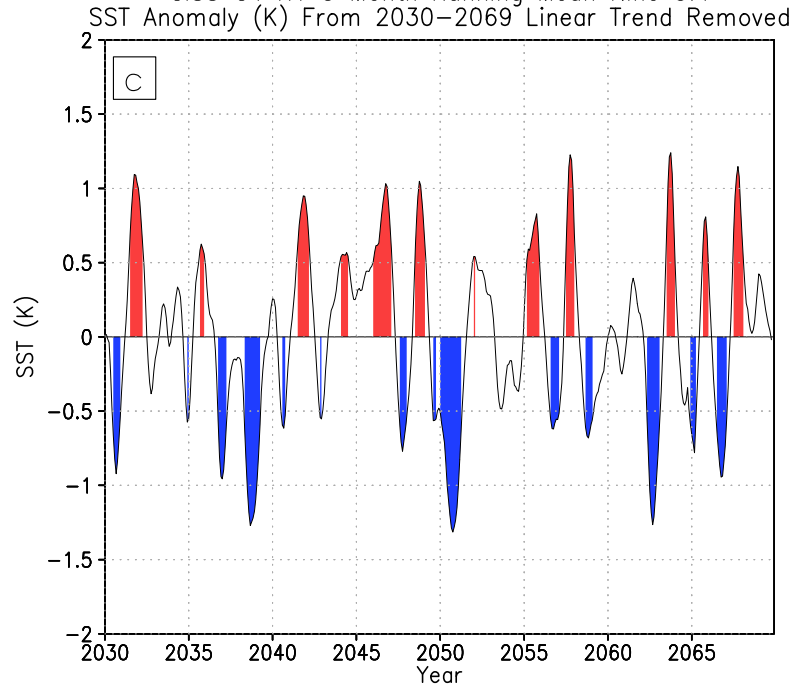

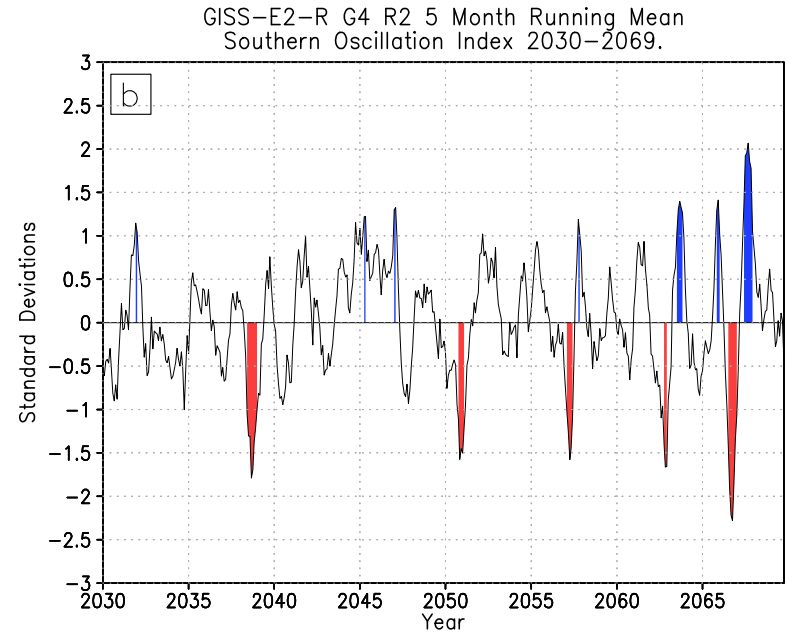

GISS G4 R2 5 Month Running Mean Nino 3.4

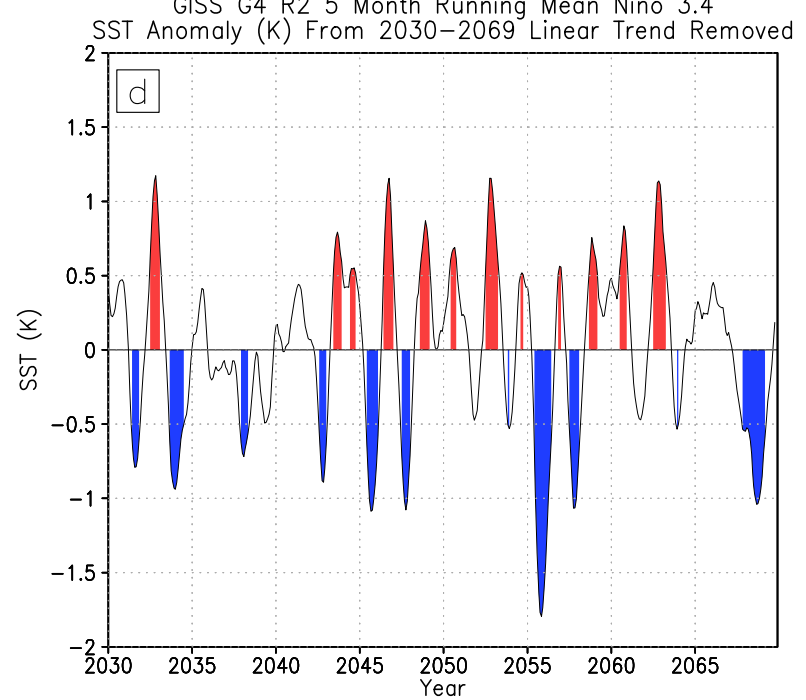

Figure 3. Time series of normalized Southern Oscillation Index (SOI) for (a) GISS G4 run 1 and (b) GISS G4 run 2. In the context of SOI, ENSO events are defined as departures of 0.5 standard deviations from 0 . SOI warm events are highlighted in red, while cold events are highlighted in blue. No highlight is applied during an ENSO neutral phase. Time series of SST in Niño3.4 region for (c) GISS G4 run 1 and (d) GISS G4 run 2. The SST-based index in the bottom panel depicts more realistic ENSO variability, and therefore SOI is not used as an SST proxy.

the historical record. To do this, we calculate the linear trend in the Niño3.4 index during the period 2030-2069 for G3, G4 and RCP4.5, 1966-2005 for historical simulations and years $11-50$ for $\mathrm{G} 1, \mathrm{G} 2,+1 \% \mathrm{CO}_{2}$ and $4 \mathrm{XCO}_{2}$. Could imposition of a geoengineering regime partially or fully offset warming in Niño3.4 over a 40-year period?

\section{Results}

\subsection{Data excluded from final comparison}

Although great strides have been made in the modern GCMs' ability to depict a realistic ENSO cycle, not all models are yet able to simulate a realistic ENSO cycle. Prior to fur- ther analysis, we applied two simple amplitude-based filters to exclude unreasonable ENSO time series data. The BNUESM output was excluded, because runs from more than one of several experiments found unrealistic 40-year ENSO time series where the substantial portion of warm and cold events maximum amplitude exceeded $3 \mathrm{~K}$. Some BNU-ESM events exceeded $4 \mathrm{~K}$, nearly a factor of 2 greater than the largest amplitude warm or cold events in the observational record. The model also produced nearly annual swings from implausibly strong warm events to cold events and back, implying an almost constant non-neutral state (Fig. 4).

The MIROC-ESM and MIROC-ESM-CHEM output were also both excluded. Runs from more than one experiment in those models resulted in unrealistic 40-year ENSO time se- 

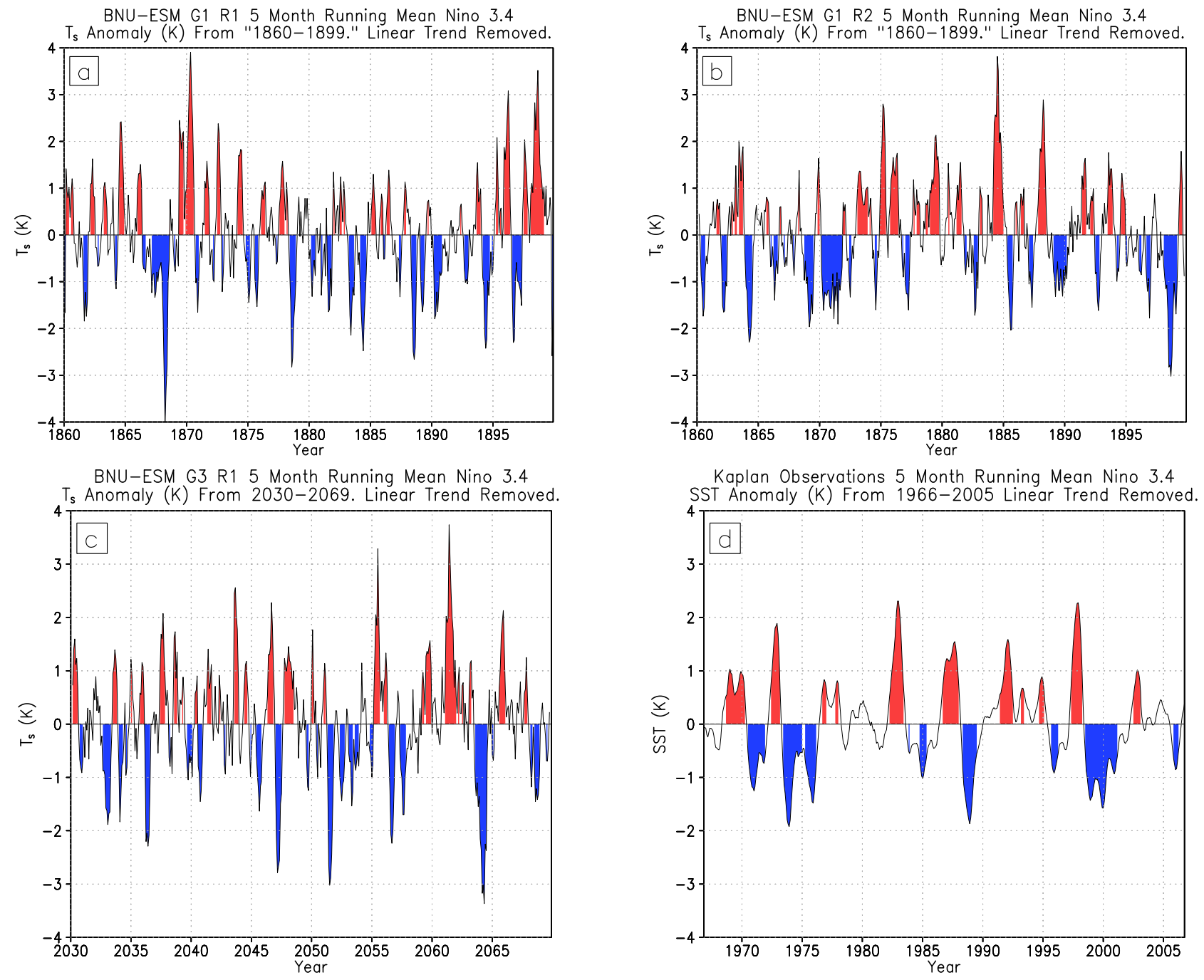

Figure 4. Time series of Niño3.4 anomalies from three experimental runs: (a) G1 run 1, (b) G1 run 2 and (c) G3 run 1, of the BNU-ESM model compared to observations (d). Red coloring indicates ENSO warm events, while blue shading indicates ENSO cold events. The model is excluded due to unrealistic variability and amplitude.

ries without a single positive anomaly of more than $1 \mathrm{~K}$ of the Niño3.4 index. Negative anomalies were similarly suppressed in simulations from both models (Fig. 5).

\subsection{Analysis}

We considered output from six GeoMIP participating GCMs: CanESM, CSIRO, GISS, HadGEM, IPSL and MPI (Tables 1 and 2). As an initial test of model performance, we first evaluated agreement between the models used and the observational record. We found good agreement between 150 years of model data and the full observational record dating back 150 years. The strong agreement between simulations and observations includes the period after 1960, when the spatial and temporal density of Niño3.4 in situ observations increased dramatically. Specifically, the 1966-2005 observa- tional record shows nine warm events, eight cold events, a maximum warm amplitude of $2.3 \mathrm{~K}$ and a maximum cold amplitude of $1.9 \mathrm{~K}$. A multi-model ensemble of historical simulations of the same period shows $9.0( \pm 1.9)$ warm events, $8.5( \pm 1.7)$ cold events, maximum warm amplitude of $1.9( \pm 0.5) \mathrm{K}$ and maximum cold amplitude of $1.7( \pm 0.6) \mathrm{K}$.

We also compared several selected 40 -year periods from the historical simulations with historical simulations and observations from different 40-year periods in order to assess ENSO variability within the historical record. Are there 40year periods in the historical record where ENSO variability is different than other 40 -year periods, and, if so, is our detection method sensitive enough to detect the difference? The statistically significant differences ( $90 \%$ confidence) found are for comparisons made between warm event frequency between 1966 and 2005 and warm event frequency 

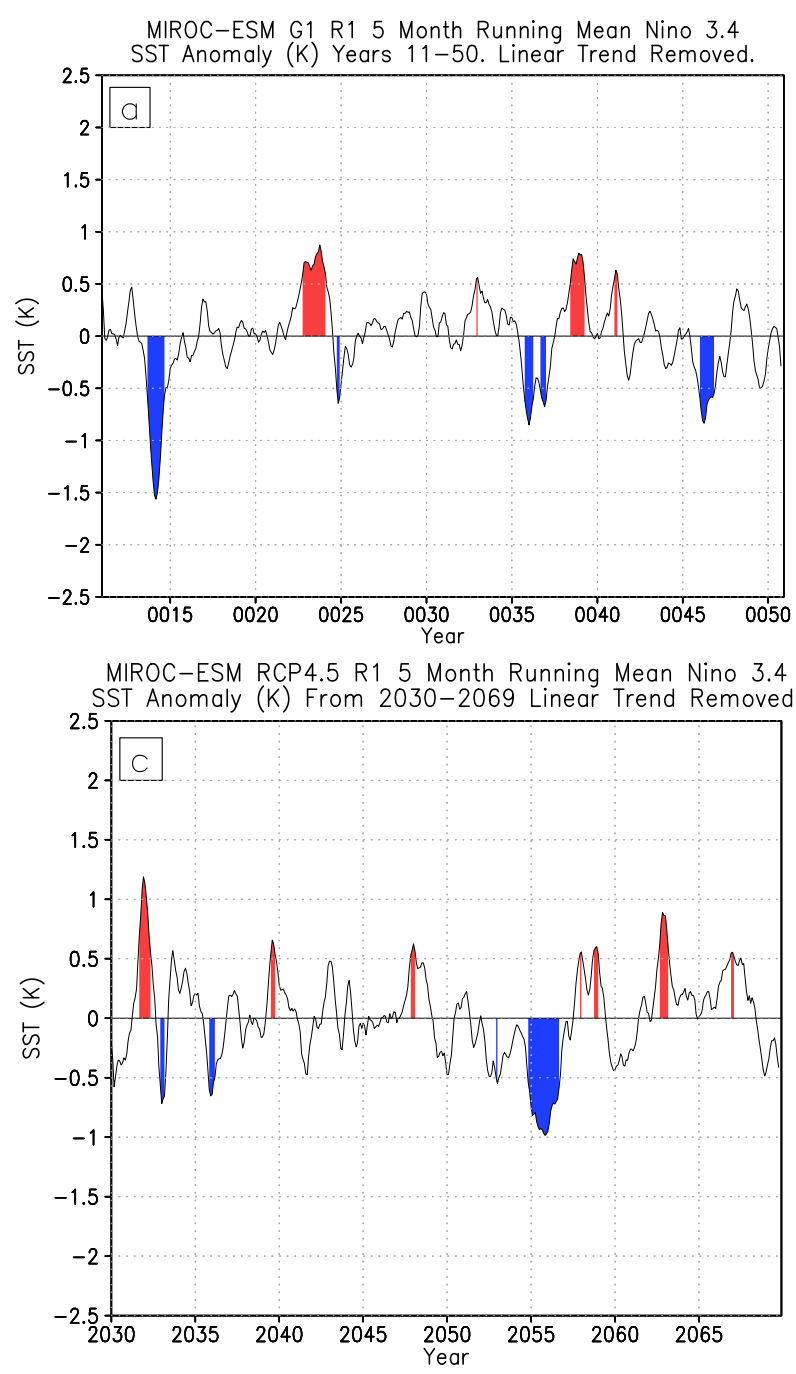

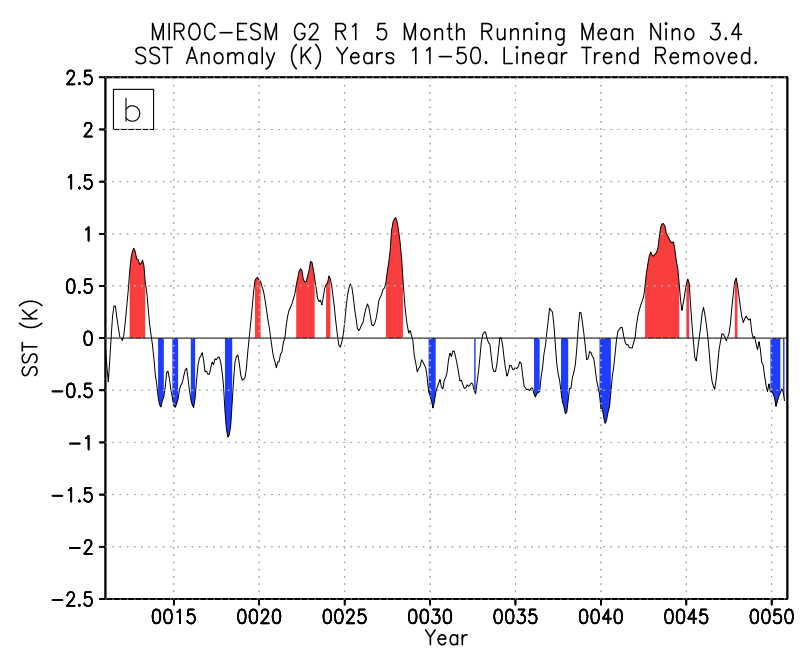

Kaplan SST Obs. 5 Month Running Mean Nino 3.4

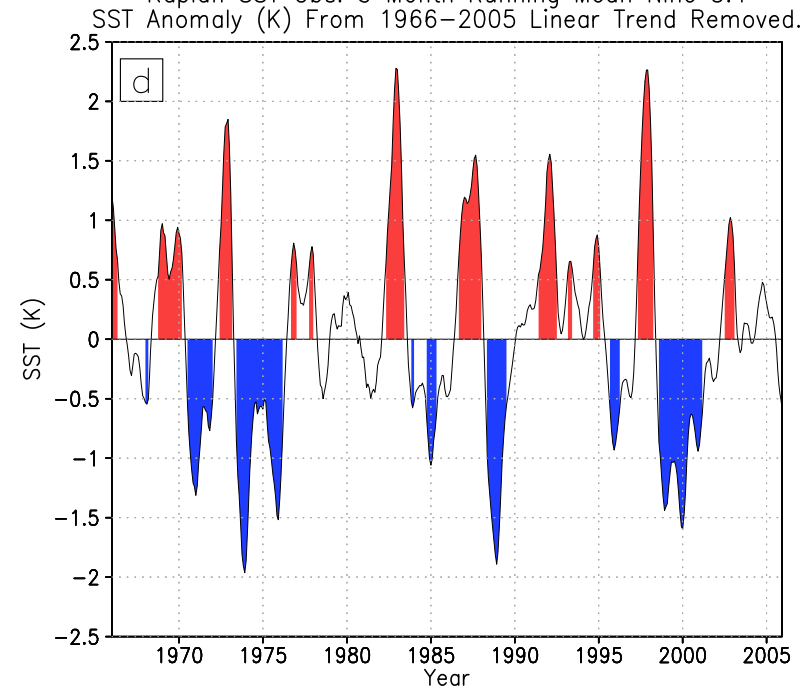

Figure 5. Niño3.4 anomalies for MIROC-ESM. Time series of (a) G1, (b) G2 and (c) RCP4.5 from each model all show significantly muted variability and amplitude compared to (d) observations, with few, if any, warm events exceeding a $1 \mathrm{~K}$ anomaly. All other MIROC family experiments showed the same muted variability. Cold event amplitude is essentially muted, with no $1 \mathrm{~K}$ or greater departures. The inability of the MIROC-ESM to depict a plausible ENSO cycle is also seen in the MIROC-ESM-CHEM. Therefore, both sets of model output were excluded.

between 1866 and $1905(p=0.07)$ or 1916 and 1955 ( $p=$ $0.06)$. There is good agreement between models and observations throughout the record and this includes extremely close agreement between 1966-2005 historical simulations and the 1966-2005 observations in terms of ENSO warm event frequencies being elevated relative to the rest of the period. This also lends support to the validity of the 1966-2005 enhanced warm event finding. While the overall fit between historical models and observations is excellent, there is a good deal of model spread (see Figs. 6-8).

We believe this finding to be robust in part because it is buttressed by the results of numerous studies using various combinations of observations and proxy records and historical modeling to reconstruct past ENSO behavior. A number of studies show similar findings about enhanced ENSO variability in the late 20th century. For example, Gergis and Fowler (2006) show that late-20th-century El Niño frequency and intensity is significantly greater than it had been at any point since 1525 . They further demonstrate that the post1940 period accounts for between 30 and $40 \%$ of extreme and protracted El Niño events (Gergis and Fowler, 2006). Li et al. (2013) used 700 years of tree ring records from multiple locations to show that ENSO activity has been unusually high in the late 20th century. Additionally, a synthesis of multiple proxies over the past 400 years showed that the period 1979-2009 was more active than any 30-year period from 1600 to 1900 (McGregor et al., 2013). Based on 7000 coral records, late-20th-century ENSO is unusually strong, $42 \%$ greater than the 7000-year average (Cobb et al., 2013). However, we cannot conclude that the unusually strong ENSO 

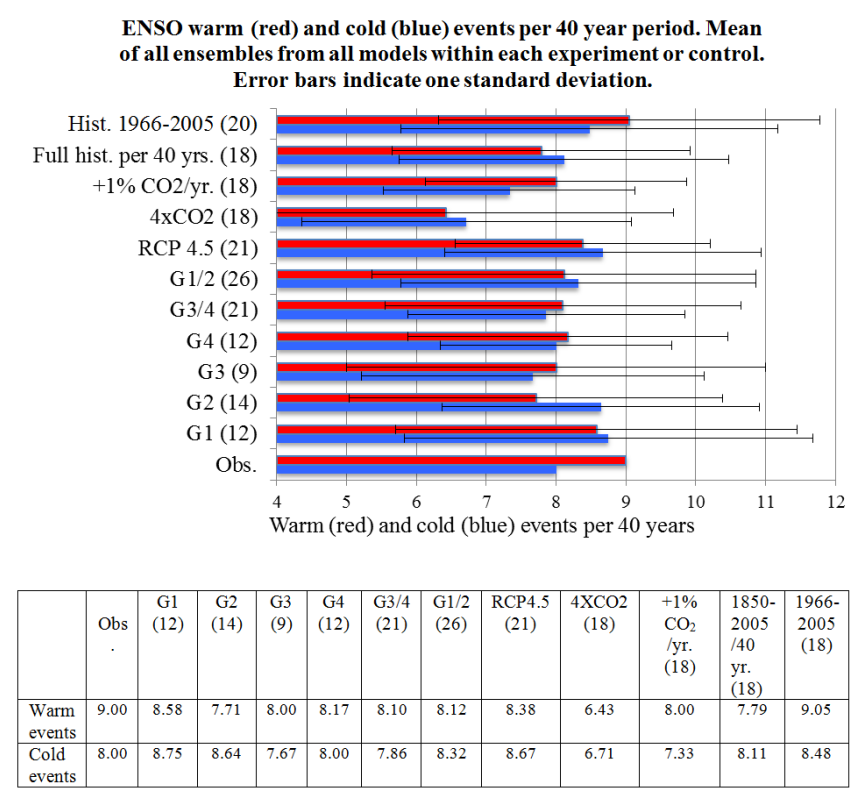

Figure 6. Number of ENSO warm (red) or cold (blue) events simulated or observed between 2030 and 2069 for G3, G4 and RCP4.5; years 11 and 50 for $\mathrm{G} 1, \mathrm{G} 2,+1 \% \mathrm{CO}_{2} \mathrm{yr}^{-1}$ increase and $4 \mathrm{XCO}_{2}$; and 1966 and 2005 for historical simulations and observations for the CanESM, CSIRO, GISS, HadGEM, IPSL and MPI models. The full historical record spans 1850-2005 and the number of events reported for this period is the per 40-year frequency of warm or cold events in this full record. Values in parentheses are the number of ensemble members for each experiment or family of experiments. Error bars represent \pm 1 standard deviation of ENSO events relative to the experiment mean. A table of values is provided under the graph.

variability in the late 20th century is the result of anthropogenic forcing, as there are other periods in the extended record where ENSO is either significantly enhanced or suppressed.

This finding from the historical record may not be germane to geoengineering, but it does test the limits of our method's detectability threshold and also demonstrates that ENSO behavior has exhibited significantly different properties during distinct portions of the historical record. A formal analysis of what percentage increase or decrease in ENSO event amplitude or frequency would be detectable given a particular sample size of 40-year runs is provided in the discussion section below.

We now turn back to the thrust of this paper, attempting to detect whether or not ENSO variability under a regime of geoengineering is distinct from ENSO variability under AGW. To do this, we perform a series of comparisons. First, each experiment, G1-G4, is matched with and compared to its respective control simulation, to the 1966-2005 historical period (during which observations are spatially and temporally dense) and to the full 150 years of available historical simulations. We find that there are no statistically significant

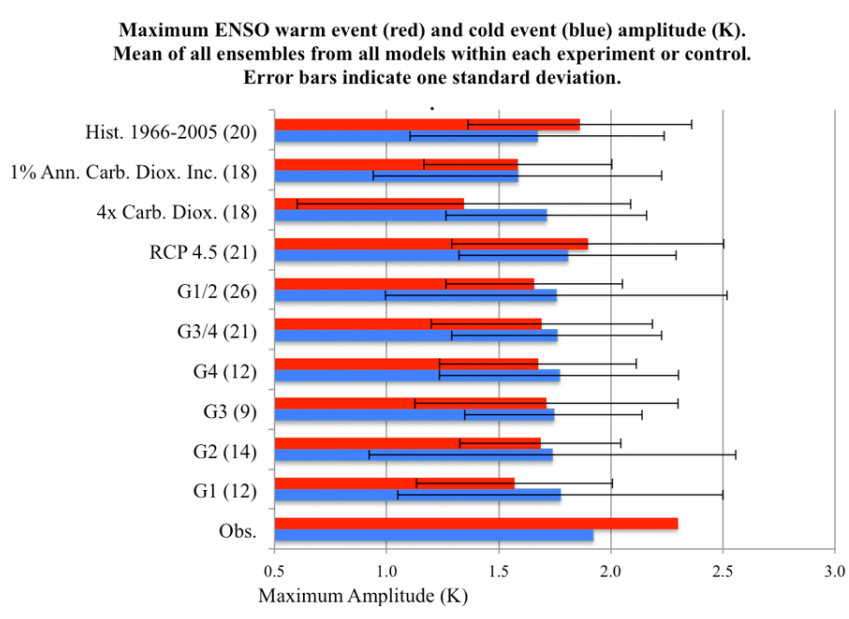

\begin{tabular}{|c|c|c|c|c|c|c|c|c|c|c|c|}
\hline & Obs & $\begin{array}{c}\text { G1 } \\
(12)\end{array}$ & $\begin{array}{c}\mathrm{G} 2 \\
(14)\end{array}$ & $\begin{array}{c}\mathrm{G} 3 \\
(9)\end{array}$ & $\begin{array}{c}\mathrm{G} 4 \\
(12)\end{array}$ & $\begin{array}{c}\mathrm{G} 3 / 4 \\
(21)\end{array}$ & $\begin{array}{c}\mathrm{G} 1 / 2 \\
(26)\end{array}$ & $\begin{array}{c}\mathrm{RCP} 4.5 \\
(21)\end{array}$ & $\begin{array}{c}4 \mathrm{XCO} 2 \\
(18)\end{array}$ & $\begin{array}{c}+1 \% \\
\mathrm{CO}_{2} / \mathrm{yr} . \\
(18)\end{array}$ & $\begin{array}{c}1966- \\
2005 \\
(18)\end{array}$ \\
\hline $\begin{array}{c}\text { Warm } \\
\text { amp. }\end{array}$ & 2.30 & 1.57 & 1.69 & 1.71 & 1.68 & 1.69 & 1.66 & 1.90 & 1.35 & 1.58 & 1.86 \\
\hline $\begin{array}{c}\text { Cold } \\
\text { amp. }\end{array}$ & 1.92 & 1.77 & 1.74 & 1.74 & 1.77 & 1.76 & 1.76 & 1.81 & 1.71 & 1.58 & 1.67 \\
\hline
\end{tabular}

Figure 7. Maximum amplitude (K) of ENSO warm (red) or cold (blue) events simulated or observed between 2030 and 2069 for G3, G4 and RCP4.5; years 11 and 50 for G1, G2, $+1 \% \mathrm{CO}_{2} \mathrm{yr}^{-1}$ increase and $4 \mathrm{XCO}_{2}$; and 1966 and 2005 for historical simulations and observations. Values in parenthesis following $y$ axis (model name) labels indicate the number of ensemble members, inclusive of all experiment designs, run by the particular model. Error bars show \pm 1 standard deviation relative to the model mean. A table of values is provided under the graph.

differences in ENSO frequency or amplitude between G1G4 and their respective controls or from the observations or historical simulations. Because only six CMIP5 GeoMIP models produce a reasonable ENSO, we have a limited number of ensemble members available with which to perform comparisons. This limits our ability to detect differences and leads us to make some suggestions in the discussion section about future GeoMIP experiments.

The criteria used for aggregating experiments are provided in the methods section above. The purpose of aggregation is to construct the largest possible ensemble of simulations, which can then be compared. The inherent variability and usually subtle character of changes in ENSO compels the use of as many data as possible to filter out all of the internal variability and detect the ENSO change attributable to a particular forcing. Based on the aggregation criteria, we are only able to aggregate G1 with G2 and G3 with G4. In the $\mathrm{G} 1 / 2$ comparisons with $4 \mathrm{XCO}_{2}$, we see significantly more frequent ( $90 \%$ confidence) La Niña events $-8.32 \pm 2.5$ per 40 years for $\mathrm{G} 1 / 2$ and $6.71 \pm 1.7$ for $4 \mathrm{XCO}_{2}$. We also see more frequent (90\% confidence) La Niña events in the G1/2 ensemble than in the $1 \%$ annual $\mathrm{CO}_{2}$ increase ensembles $8.32 \pm 2.5$ per 40 years for $\mathrm{G} 1 / 2$ and $7.37 \pm 1.7$ for $1 \%$ annual $\mathrm{CO}_{2}$ increase. 


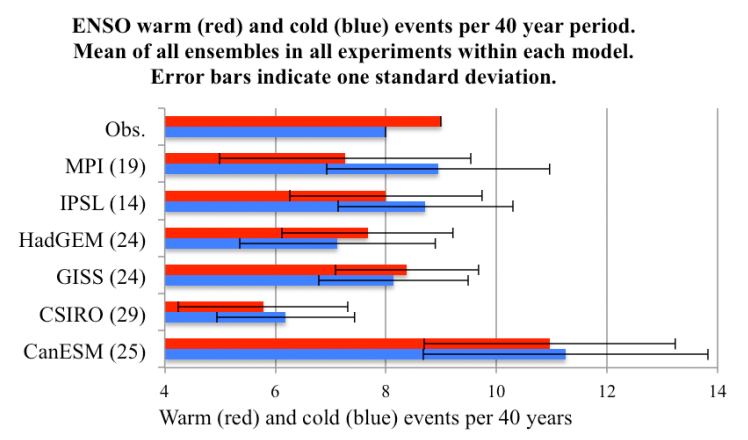

\begin{tabular}{|c|c|c|c|c|c|c|c|}
\hline & Obs. & $\begin{array}{c}\text { CanESM } \\
(25)\end{array}$ & $\begin{array}{c}\text { CSIRO } \\
(25)\end{array}$ & GISS (24) & $\begin{array}{c}\text { HadGEM } \\
(24)\end{array}$ & IPSL (14) & MPI (19) \\
\hline $\begin{array}{c}\text { Warm } \\
\text { Events }\end{array}$ & 9.00 & 10.96 & 5.78 & 8.38 & 7.67 & 8.00 & 7.26 \\
\hline $\begin{array}{c}\text { Cold } \\
\text { Events }\end{array}$ & 8.00 & 11.25 & 6.19 & 8.14 & 7.13 & 8.71 & 8.95 \\
\hline
\end{tabular}

Figure 8. Number of ENSO warm (red) or cold (blue) events observed or simulated in the applicable 40-year comparison period for the CanESM, CSIRO, GISS, HadGEM, IPSL and MPI models. Values in parentheses are the number of ensemble members for each experiment or family of experiments. Error bars represent \pm 1 standard deviation of ENSO events relative to the experiment mean. A table of values is provided under the graph.

Since a number of comparisons were made and confidence in these results being significant is only $90 \%$, we decided to apply a simple resampling technique to test the robustness of these results. First, we chose a sample, with replacement, from the G1/2 ensembles. Next, we chose a sample, with replacement, from $4 \mathrm{XCO}_{2}$. After calculating the median of each of the two samples, we repeated this process 500 times. Next, we calculated the differences between the medians in each of the 500 samples. This gives us an array of 500 integers, which are the differences between medians. The 25 highest and lowest differences between medians are stored, and the remaining 450 integers form a $90 \%$ confidence interval. Since the difference between the means in the G1/2 ensemble and the $4 \mathrm{XCO}_{2}$ ensemble fall within the $90 \%$ confidence interval of differences between means that we obtained via resampling, we conclude that the result showing increased ENSO frequency in G1/2 relative to control was likely obtained by chance. The same process was carried out for the $\mathrm{G} 1 / 2$ comparison with $1 \%$ annual $\mathrm{CO}_{2}$ increase. $\mathrm{Al}-$ though the original comparison showed a significant result (90\% confidence), after resampling, the difference between the $\mathrm{G} 1 / 2$ and $1 \%$ annual $\mathrm{CO}_{2}$ means was shown to be within the $90 \%$ confidence interval. Therefore, despite the initial presentation of results, based on a simple resampling technique, which allows for replacement, we find that there are no significant differences between G1/2 and the applicable controls.

Next, we turn to the final aggregated comparison, G3/4 and RCP4.5. Among all experiments and control simulations RCP4.5 simulations showed both the strongest and most frequent ENSO events. However, error bounds are large due to relatively small sample size $(n=21)$ for RCP4.5 and G3/4, and no difference in ENSO frequency or amplitude was detected in this comparison.

These results show the absence of a significant difference between GeoMIP experimental runs and AGW runs. However, the comparisons were limited by a number of factors. First, we excluded simulations from several GeoMIP participating modeling groups due to an implausible ENSO in the models. Second, current generation GeoMIP runs may not be long enough to detect changes in ENSO. Third, the signal-tonoise ratio in RCP4.5 is rather low. A geoengineering experiment that seeks to offset a stronger forcing may improve our chances detecting potential changes in future ENSO. These detectability issues will be covered in greater detail in Sect. 4 .

\subsection{Comparisons between models}

One of the features most readily apparent across all models was the confinement of the most robust coupling between the ocean and the atmosphere too close to the Equator and not extending as far eastward as in observations. The ENSO center of action was over a small area in the central Pacific, whereas the center of action extended further into the equatorial eastern extent of the basin in the observational record (Fig. 2).

Next we make model vs. model comparisons - comparing all ensemble members of runs from each model against each other. Figures 8 and 9 show ENSO event amplitude and frequency simulated by each model. Of the models not excluded, the CanESM results diverged far more than the other models from the overall mean on all four parameters evaluated. CanESM depicts ENSO warm and cold events that are both more frequent and stronger than those documented in the Kaplan et al. (1998) SST observational record. The CSIRO model depicts the lowest number of both cold and warm events, as well as event amplitudes that are on the low end. The GISS, HadGEM, IPSL and MPI models are not in close agreement on all four parameters, but they agree more than the CSIRO and CanESM. The best agreement between models existed between the GISS, HadGEM, MPI and IPSL, which agreed on all but cold event amplitude. Had we excluded the CanESM (most frequent and strongest ENSO events) and CSIRO models (least frequent ENSO events), agreement between the remaining four models would have been reasonable. However, both the CanESM and CSIRO produce a physically plausible ENSO. During especially active periods, ENSO has behaved in line with the CanESM results. During relatively quiescent periods in the observational record, the CSIRO results are not out of line with observations. 


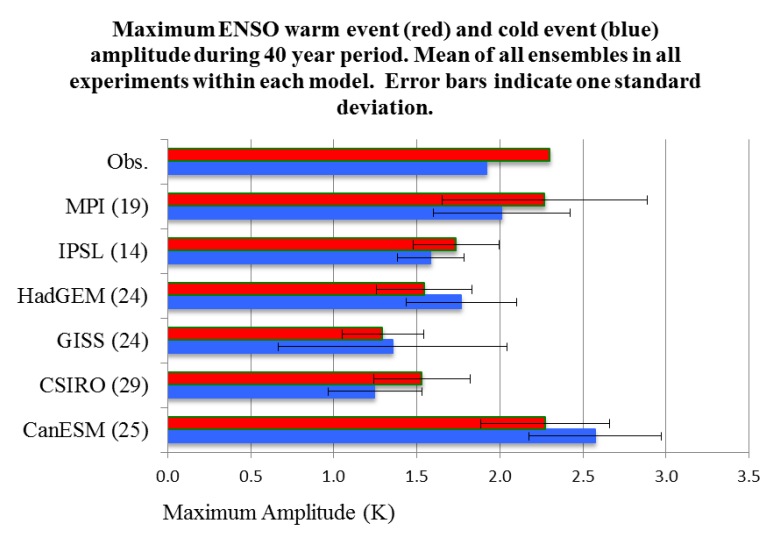

\begin{tabular}{|c|c|c|c|c|c|c|c|}
\hline & Obs. & $\begin{array}{c}\text { CanESM } \\
(25)\end{array}$ & $\begin{array}{c}\text { CSIRO } \\
(25)\end{array}$ & GISS (24) & $\begin{array}{c}\text { HadGEM } \\
(24)\end{array}$ & IPSL (14) & MPI (19) \\
\hline $\begin{array}{c}\text { Warm } \\
\text { amp. }\end{array}$ & 2.30 & 2.27 & 1.53 & 1.29 & 1.54 & 1.74 & 2.27 \\
\hline $\begin{array}{c}\text { Cold } \\
\text { amp. }\end{array}$ & 1.92 & 2.57 & 1.25 & 1.35 & 1.77 & 1.58 & 2.01 \\
\hline
\end{tabular}

Figure 9. Maximum amplitude (K) of ENSO warm (red) or cold (blue) events observed or simulated in the applicable 40-year comparison period. Values in parenthesis following $y$ axis (model name) labels indicate the number of ensemble members, inclusive of all experiment designs, run by the particular model. Error bars show \pm 1 standard deviation relative to the model mean. A table of values is provided under the graph.

\subsection{Long-term behavior of Niño3.4 under geoengineering}

While ENSO is a dominant source of interannual variability both in the tropical Pacific and globally, the evolution of conditions in the Niño3.4 region on timescales much longer than that of ENSO are also of importance to regional and global climate. Individual ENSO events are modulated by the complex interaction of positive and negative feedbacks. The long-term trend in SSTs in this region is heavily influenced by other sources natural variability on decadal timescales. However, over a 40 -year period of global warming or geoengineering, the SST trend in this region will be largely dependent on anthropogenic forcing or the combination of geoengineering and anthropogenic forcing. In order to examine the change in Niño3.4 over the full duration of each experiment, we calculate the linear trend of warming or cooling in the Niño3.4 index over the applicable 40-year period. The linear trends are calculated over 2030-2069 for G3, G4 and RCP4.5 and over years $11-50$ for $\mathrm{G} 1, \mathrm{G} 2,4 \mathrm{XCO}_{2}$ and $+1 \%$ $\mathrm{CO}_{2} \mathrm{yr}^{-1}$ (Table 3, Fig. 10).

The objective of geoengineering is to cool the Earth's surface sufficiently so as to offset some of the negative impacts of global warming. The amount of temperature change expected over an extended period of geoengineering as opposed to under AGW alone is an obvious indicator of the potential efficacy of geoengineering in a particular region. SSTs over Niño3.4 region change considerably under global warming
Table 3. Difference in linear trend of Niño3.4 index $\left(5^{\circ} \mathrm{S}-5^{\circ} \mathrm{N}\right.$, $120-170^{\circ} \mathrm{W}$ ) between each experiment G1-G4 and its control.

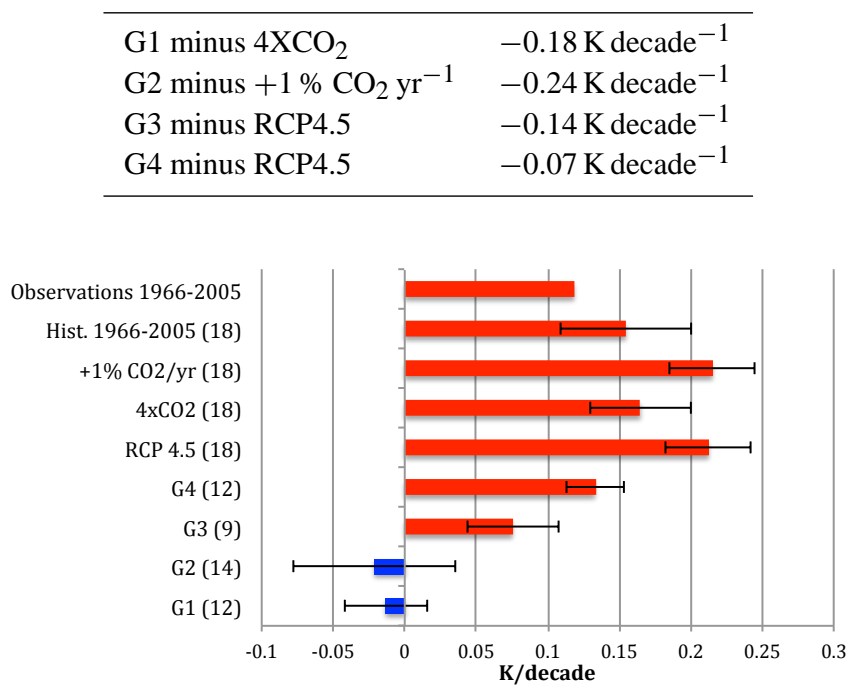

Figure 10. Linear trend in Niño3.4 index $\left(5^{\circ} \mathrm{S}-5^{\circ} \mathrm{N}, 120-170^{\circ} \mathrm{W}\right)$ during the applicable 40-year comparison periods. The applicable comparison periods are 1966-2005 for historical simulations; years $11-50$ for $\mathrm{G} 1, \mathrm{G} 2,+1 \% \mathrm{CO}_{2} \mathrm{yr}^{-1}$ and $4 \mathrm{XCO}_{2} ; 2030-2069$ for G3, G4 and RCP4.5; and 1966-2005 for historical simulations and observations. The values in parenthesis are the number of ensemble members for each experiment. Red bars indicate a warming trend. Blue bars indicate a cooling trend. Error bars indicate 1 standard deviation.

and under some geoengineering scenarios. Under G1 and G2, the linear trend of SSTs in Niño3.4 is negative and very close to 0 . In both experiments, a $\mathrm{CO}_{2}$ increase is imposed on a steady-state preindustrial climate concurrently with a fully offsetting solar constant reduction. G1 and G2 generally depict little change in global mean temperature. In terms of variability between models simulations of Niño3.4 linear trend, the coarsest error bars can be found with the G1 and G2 experiment. Climate was fully stabilized in most runs, but some runs exhibited evidence of either a warming or cooling trend.

G3 and G4 initialize from a warming climate and seek to offset RCP4.5 with $\mathrm{SO}_{2}$ injections. In both experiments, the Niño3.4 region continues to warm despite the $\mathrm{SO}_{2}$ injections. In $\mathrm{G} 3$ the warming trend is $0.07 \mathrm{~K} \mathrm{decade}^{-1}$. However, the $\mathrm{G} 3$ experiment is designed so that the RCP4.5 warming is fully offset to generate 0 net forcing. Offsetting radiative forcing by injecting a layer of stratospheric aerosols does not prevent continued warming in the ocean. Put simply, the ocean has a huge thermal mass. Rising or falling air temperatures take time before their impact is felt in the ocean.

For G4, the initial $\mathrm{SO}_{2}$ forcing is fully offset at first, but during the experiment the amount of $\mathrm{SO}_{2}$ being injected into the atmosphere does not change, even as the RCP4.5 forcing grows. Therefore, it is unsurprising that Niño3.4 continues 
to warm under G4. However, the trend of $0.13 \mathrm{~K} \mathrm{decade}^{-1}$ is rather robust and is only a $23 \%$ weaker than the trend observed from 1966 to 2005 of $0.16 \mathrm{~K} \mathrm{decade}^{-1}$.

Only the geoengineering scenarios that are physically implausible (G1-G2) fully offset global warming induced SST changes in Niño3.4. The more realistic scenarios (G3 and G4) are able to significantly reduce the magnitude of warming under RCP4.5. The RCP4.5 warming trend of $0.21 \mathrm{~K} \mathrm{decade}^{-1}$ is 3 times stronger than $\mathrm{G} 3$ and $62 \%$ stronger than the warming trend seen in the G4 experiment, which is the experiment that best reflects the process by which stratospheric geoengineering would actually be deployed in the real world.

The warming trends are $0.22 \mathrm{Kdecade}^{-1}$ in $+1 \%$ $\mathrm{CO}_{2} \mathrm{yr}^{-1}$ and $0.17 \mathrm{~K} \mathrm{decade}^{-1}$ in $4 \mathrm{XCO}_{2}$. Our results about the evolution of Niño3.4 warming under $4 \mathrm{XCO}_{2}$ are in line with the extensive analysis of the global $4 \mathrm{XCO}_{2}$ response described by Caldeira and Myhrvold (2013). They show that about $55 \%$ of the $4 \mathrm{XCO}_{2}$ warming occurs in the first 10 years and then a relatively slow trend develops for the next 50 years during which another approximately $15 \%$ of the total warming occurs. After about 60 years the warming flattens out substantially and it takes several hundred years for the full extent of the warming to be evident. If the total $4 \mathrm{XCO}_{2}$ warming is $6 \mathrm{~K}$, we would expect about 10 to $15 \%$ $(0.6$ to $0.9 \mathrm{~K})$ of that to occur over our experimental period.

The key finding in our experiment with regard to the longterm behavior of the Niño3.4 index is that under RCP4.5 the warming trend will be $62 \%$ stronger between 2030 and 2069 than if we impose geoengineering as simulated by G4 beginning in 2020.

\section{Discussion}

We conclude that changes in ENSO event frequency and amplitude in a geoengineered world relative to the historical record, global warming simulations and the observational record are either not present or not large enough to be detectable using the approach employed in this experiment and described in the methods section above. However, this conclusion comes with a number of very strong caveats, including the relatively brief simulation length and the considerable model spread. Despite the absence of a detectable change in ENSO amplitude and frequency in our experiments, we take this opportunity to explicitly state the conditions under which changes in ENSO variability could have been detected. Therefore, we assess the sensitivity of our method for identifying differences in ENSO frequency and amplitude between an experiment and its control. We begin by calculating the minimum increase in event frequency or amplitude that would be detectable.

Since GISS is a relatively well-performing model, and the standard deviation of event amplitude and frequency is relatively low, we address the minimum detectability issue with the GISS model first. We take the GISS runs and randomly assign each simulation into one of two groups of 11 . The random assignment to each group is repeated many times. The amplitude and frequency statistics of the two groups are then compared using a two-sample $t$ test assuming unequal variance. We select the comparison that generates a probability of wrongly rejecting the hypothesis that there is no difference between the means that is closest to but not greater than 0.05 (0.03-0.05 in all cases). This corresponds to a significant result at the $95 \%$ level. The difference between these two means, expressed as a percentage increase, is then reported as the threshold value of detectable change in ENSO frequency or amplitude.

In the GISS model, to detect a $31 \%$ increase in El Niño frequency, two groups of 11 ensembles of 40-year simulations are required. A $26 \%$ increase in La Niña event frequency is required for detectability. In terms of amplitude, an $18 \%$ increase in El Niño amplitude was detectable, as was a $17 \%$ increase in La Niña frequency.

We then use the same approach to test the minimum detectability threshold in the CSIRO model; we expect to find increased sensitivity to changes in event frequency but not necessarily to amplitude. In fact, a $25 \%$ increase in warm event frequency and a $21 \%$ increase in cold event frequency are both detectable. The ENSO event amplitude detectability threshold in CSIRO is close to that found in the GISS model: $17 \%$ for warm events and $16 \%$ for cold events.

Lastly, we examine the CanESM model, which featured the largest and most frequent ENSO events but also featured close agreement between ensemble members. The thresholds for detectability for the CanESM are increases of $16 \%$ for both warm and cold event frequency, $18 \%$ for an increase in warm event amplitude and $15 \%$ for an increase in cold event amplitude. A priority in subsequent experiments would be to reduce the detectability thresholds. For the purposes of improving detectability, steady-state simulations that simulate 100 years or more of geoengineering in which a large $\mathrm{CO}_{2}$ forcing is offset would likely be of most interest for additional detailed analysis, especially if a large number of simulations were available. This has been proposed for future GeoMIP experiments (Kravitz et al., 2015).

The next generation of GeoMIP experiments that will be part of CMIP6 will extend G1 simulations to 100 years and also provide simulations in which a more extreme AGW scenario - RCP6 or RCP8.5 - is offset by constant stratospheric sulfate injections or solar dimming. These new experimental designs result from the need to understand extreme precipitation and temperature events, changes in regional climate and to examine modes of internal variability (Kravitz et al., 2015).

A potential future GeoMIP experiment could apply our detection methodology and proceed as follows. Compare the 100 -year $4 \mathrm{XCO}_{2}$ scenario with 100 years of preindustrial control and G1 (G1extended; Kravitz et al., 2015). Given the length of this simulation and the large differences in depic- 
tion of future climate between $4 \mathrm{XCO}_{2}, \mathrm{G} 1$ and the preindustrial control, this would likely be the comparison most likely to show a difference sufficient to exceed our detectability threshold.

Should a signal be detectable in G1extended, the G6solar or G6sulfur experiments, which will run for at least 80 years without termination, offsetting either RCP6.0 or RCP8.5 with continuous sulfate injections or solar dimming, should be evaluated next. The presence of a signal in the steadystate G1extended experiment would be more likely than in the transient G6 experiments. However, the G6solar and G6sulfur scenarios are far more like real climate, and although detecting a difference in G6 would likely be more difficult than in G1extended, a G6 signal would speak more directly to how the tropical Pacific might evolve under plausible future geoengineering scenarios. We would also recommend comparing the extended GeoMIP simulation results to the late-20th-century ENSO record. Even after the next generation of GeoMIP simulations has been released, the ability of those experiments to potentially detect future changes in ENSO variability will still be limited by how well each model performs.

We now turn to another important issue that hinders detectability of changes in ENSO variability: the ability of current generation GCMs to accurately reproduce ENSO. Substantial work has been done to determine why many models have difficulty simulating an ENSO that matches observations in amplitude and frequency. The Climate and Ocean: Variability, Predictability and Change (CLIVAR) ENSO working group's analysis of process-based variables in CMIP 3/5 - which quantifies a GCM's ability to simulate key ENSO processes - is underway (Guilyardi, 2012). That work is more squarely focused on determining exactly how the simulation of both ENSO events and the underlying ENSO processes can be improved in GCMs. However, we can evaluate the ENSO behavior we saw in this geoengineering experiment in the context of the process-based variable analysis conducted by CLIVAR.

In the CSIRO model we see lower variability than in other models and slightly dampened amplitude. We also noticed that the center of action in terms of ENSO variability is shifted somewhat westward. This is in line with Bellenger et al. (2013), who found that the standard deviation of SST in Niño4 is far greater than that seen in Niño3. In the GISS and other models ocean-atmosphere coupling as reflected by the SST/SOI correlation was very robust in Niño3.4 at the Equator but somewhat muted elsewhere. The area in which coupling between the ocean and atmosphere is most robust did not extend throughout Niño3.4, and therefore areas farther away from the Equator and further east were not contributing as much to the Niño index. Therefore we see slightly lower Niño3.4 amplitude values in GISS and HadGEM than we do in other models. The presence of this tendency is bolstered by Guilyardi (2012), who showed that the standard deviation of SST in both Niño3 and Niño4 is toward the low end of the range for CMIP5 models. In our experiment, the IPSL model performs very well in terms of a realistic ENSO frequency and amplitude. This tendency is also reinforced by Guilyardi (2012), who showed that the root mean square error is among the lowest of CMIP5 models for both SST and surface wind stress. Even though different models struggle with various ENSO processes, the tendencies of each model are relatively well understood and each model generated an ENSO that is plausible, albeit not necessary exactly fit to what is seen in the observational record.

However, the story for the models excluded is quite different. A representative BNU G1 run showed a cold event with a maximum anomaly of $-4.8 \mathrm{~K}$ during a relatively short duration La Niña event. Similar non-geoengineering runs revealed equally extreme amplitude and short-lasting events. The observational record fails to hint that such an event has occurred, and none of the other models simulate anything like such an event. Future work could explore why simulated BNU ENSO events are so strong, short and frequent relative to observations and other models.

Since the ENSO mechanism is so vulnerable to small perturbations, subtle differences in how forcing is applied could impact the ENSO mechanism in the models. Specifically, emissions are imposed differently in the historical runs from how they are imposed in RCP4.5. RCP4.5 emissions are imposed decadally, while historical models incorporate gridded monthly data. There is likely a modest amount of interannual variability in tropical Pacific SST that is omitted from RCP4.5 simulations due to the decadal smoothing of emissions. Subsequent research focused on RCP4.5 ENSO variability could seek to determine if the interannual variability in SSTs is muted enough by this smoothing in RCP4.5 to potentially alter the evolution of ENSO events.

While our results pertaining specifically to changes in ENSO frequency and amplitude reveal that detectability of changes is difficult, the overall trend in Niño3.4 is clear under each potential future scenario. The most important conclusion from analysis of the long-term trend in Niño3.4 is that the warming trend in RCP4.5 would be $62 \%$ stronger than in $\mathrm{G} 4$, the most realistic geoengineering scenario. Changes in SSTs in Niño3.4 are important because the mean climate of this region is an important factor in enhancing weather and climate trends on multiple timescales. For example, the $0.9 \mathrm{~K}$ warming in Niño3.4 over 40 years under RCP4.5 would greatly enhance the amount of precipitable water in the region. Meridional transport of water vapor out of the tropics occurs through relatively narrow regions in the atmosphere. These so-called atmospheric rivers advect moisture into the baroclinic zone and are responsible for many extreme precipitation events in North America and other places.

Superposing a $0.9 \mathrm{~K}$ warmer Niño3.4 mean onto a strong El Niño event could easily result in more extreme remote ENSO impacts, such as flooding. Additionally, increased SSTs results in warmer surface air temperatures and a steeper lapse rate. This promotes broad areas of enhanced convection 
over warm ocean areas, which induce poleward propagating wave motion in the atmosphere, which alter the general circulation and change weather patterns around the world. Would a $0.9 \mathrm{~K}$ warming of Niño3.4 cause generally enhanced convection over the Niño3.4 region and would this convection induce detectable changes in the general circulation? Would the warming of only $0.5 \mathrm{~K}$ under $\mathrm{G} 4$ result in different regional and global warming impacts than the RCP4.5 warming? Certainly it is worthwhile to study how long-term trends in particular regions such as Niño3.4 may be closely related to other long-term trends in remote places and how these relationships may differ under geoengineering as opposed to AGW.

Lastly, the next generation of GeoMIP experiments will produce longer simulations, with more robust forcing in the case of G1 extended. It is imperative that we understand potential changes in extreme event frequency under geoengineering and potential changes in modes of internal variability. Any future contemplation of large-scale deployment of geoengineering would require confidence in model predictions about potential changes in natural variability and the frequency and nature of extreme events.

Acknowledgements. We thank all the climate modeling groups for conducting the GeoMIP simulations and making their output available. We thank Ben Kravitz for his overall leadership of GeoMIP. We also thank three anonymous reviewers for their thoughtful and constructive feedback. This work is supported by NSF grants AGS-1157525 and GEO-1240507.

Edited by: L. M. Russell

\section{References}

Arora, V. K., Scinocca, J. F., Boer, G. J., Christian, J. R., Denman, K. L., Flato, G. M., Kharin, V. V., Lee, W. G., and Merryfield, W. J.: Carbon emission limits required to satisfy future representative concentration pathways of greenhouse gases, Geophys.Res. Lett., 38, L05805, doi:10.1029/2010GL046270, 2011.

Bellenger, H., Guilyardi, E., Leloup, J., Lengaigne, M., and Vialard, J.: ENSO representation in climate models: from CMIP3 to CMIP5, Clim. Dynam., 42, 1999-2018, 2013.

Bjerknes, J.: Atmospheric teleconnections from the equatorial Pacific, Mon. Weather Rev., 97, 163-172, 1969.

Cai, W., Wang, G., Santoso, A., McPhaden, M., Wu, L., Jin, F.-F., Timmermann, A., Collins, M., Vecchi, G., Lengaigne, M., England, M., Dommenget, D., Takahashi, K., and Guilyardi, E.: Increasing frequency of extreme El Niño events due to greenhouse warming, Nat. Clim. Change, 4, 111-116, 2014.

Cai, W., Wang, G., Santoso, A., McPhaden, M., Wu, L., Jin, F.-F., Timmermann, A., Collins, M., Vecchi, G., Lengaigne, M., England, M., Dommenget, D., Takahashi, K., and Guilyardi, E.: Increased frequency of extreme La Niña events under greenhouse warming, Nat. Clim. Change, 5, 132-137, 2015.

Caldeira, K. and Myhrvold, N. P.: Projections of the pace of warming following an abrupt increase in atmospheric carbon dioxide concentration, Environ. Res. Lett., 8, 034039, doi:10.1088/17489326/8/3/034039, 2013.

Caldeira, K., Bala, G., and Cao, L.: The science of geoengineering, Annu. Rev. Earth Pl. Sc., 41, 231-256, 2013.

Clement, A. C., Seager, R., Cane, M. A., and Zebiak, S. E.: An ocean dynamical thermostat, J. Climate, 9, 2190-2196, 1996.

Cobb, K. M., Westphal, N., Sayani, H. R., Watson, J. T., Di Lorenzo, E., Cheng, H., Edwards, R. L., and Charles, C. D.: Highly variable El Niño-Southern Oscillation throughout the Holocene, Science, 339, 67-70, 2013.

Collins, W. J., Bellouin, N., Doutriaux-Boucher, M., Gedney, N., Halloran, P., Hinton, T., Hughes, J., Jones, C. D., Joshi, M., Liddicoat, S., Martin, G., O'Connor, F., Rae, J., Senior, C., Sitch, S., Totterdell, I., Wiltshire, A., and Woodward, S.: Development and evaluation of an Earth-System model - HadGEM2, Geosci. Model Dev., 4, 1051-1075, doi:10.5194/gmd-4-10512011, 2011.

Crutzen, P.: Albedo enhancement by stratospheric sulfur injections: A contribution to solve a policy dilemma?, Climatic Change, 77, 211-219, 2006.

D’Agostino, R. B., Belanger, A., and Ralph, B.: A suggestion for using powerful and informative tests of normality, The American Statistician, 44, 316-321, 1990.

Dai, Y., Zeng, X. B., Dickinson, R. E., Baker, I., Bonan, G. B., Bosilovich, M. G., Denning, A. S., Dirmeyer, P. A., Houser, P. R., Niu, G. Y., Oleson, K. W., Schlosser, C. A., and Yang, Z.-L.: The Common Land Model (CLM), B. Am. Meteorol. Soc., 84, 1013-1023, 2003.

Decarlo, L. T.: On the meaning and use of kurtosis, Psychol. Methods, 2, 292-307, 1997.

Dufresne, J. L., Foujols, M. A., Denvil, S., Caubel, A., Marti, O., Aumont, O, Balkanski, Y., Bekki, S , Bellenger, H., Benshila, R., Bony, S., Bopp, L., Braconnot, P., Brockmann, P., Cadule, P., Cheruy, F , Codron, F , Cozic, A , Cugnet, D., de Noblet, N., Duvel, J. P., Ethé, C., Fairhead, L., Fichefet, T., Flavoni, S., Friedlingstein, P., Grandpeix, J. Y., Guez, L., Guilyardi, E., Hauglustaine, D., Hourdin, F., Idelkadi, A., Ghattas, J., Joussaume, S., Kageyama, M., Krinner, G., Labetoulle, S., Lahellec, A., Lefebvre, M. P., Lefevre, F., Levy, C., Li, Z. X., Lloyd, J., Lott, F., Madec, G., Mancip, M., Marchand, M., Masson, S., Meurdesoif, Y., Mignot, J., Musat, I., Parouty, S., Polcher, J., Rio, C., Schulz, M., Swingedouw, D., Szopa, S., Talandier, C., Terray, P., Viovy, N., and Vuichard, N.: Climate change projections using the IPSL-CM5 Earth System Model: from CMIP3 to CMIP5, Clim. Dynam., 40, 2123-2165, 2013.

Emile-Geay, J., Seager, R., Cane, M. A., Cook, E. R., and Haug, G. H.: Volcanoes and ENSO over the past millennium, J. Climate, 21, 3134-3148, 2007.

Gergis, J. L. and Fowler, A. M.: How unusual was late 20th century El Niño-Southern Oscillation (ENSO)? Assessing evidence from tree-ring, coral, ice-core and documentary palaeoarchives, A.D. 1525-2002, Adv. Geosci., 6, 173-179, doi:10.5194/adgeo6-173-2006, 2006.

Giorgetta, M. A., Jungclaus, J. H., Reick, C. H., Legutke, S., Bader, J., Böttinger, M., Brovkin, V., Crueger, T., Esch, M., Fieg, K., Glushak, K., Gayler, V., Haak, H., Hollweg, H.-D., Ilyina, T., Kinne, S., Kornblueh, L., Matei, D., Mauritsen, T., Mikolajewicz, U., Mueller, W. A., Notz, D., Pithan, F., Raddatz, T., Rast, S., Redler, R., Roeckner, E., Schmidt, H., Schnur, R., Segschneider, 
J., Six, K., Stockhause, M., Timmreck, C., Wegner, J., Widmann, H., Wieners, K.-H., Claussen, M., Marotzke, J., and Stevens, B.: Climate and carbon cycle changes from 1850 to 2100 in MPIESM simulations for the coupled model intercomparison project phase 5, J. Adv. Model. Earth Sys., 5, 572-597, 2013.

Guilyardi, E., Wittenberg, A., Fedorov, A., Collins, M., Wang, C., Capotondi, A., Oldenborgh, G. J. V., and Stockdale, T.: Understanding El Niño in ocean-atmosphere general circulation models: progress and challenges, B. Am. Meteorol. Soc., 90, 325340, 2009.

Guilyardi, E., Bellenger, H., Collins, M., Ferrett, S., Cai, W., and Wittenberg, A.: A first look at ENSO in CMIP5, CLIVAR Exchanges, 58, 29-32, 2012.

Held, I. M. and Soden, B. J.: Robust responses of the hydrological cycle to global warming, J. Climate, 19, 5686-5699, 2006.

Held, I. M., Winton, M., Takahashi, K., Delworth, T., Zeng, F., and Vallis, G. K.: Probing the fast and slow components of global warming by returning abruptly to preindustrial forcing, J. Climate, 23, 2418-2427, 2010.

IPCC: Summary for Policymakers, in: Climate Change 2013: The Physical Science Basis. Contribution of Working Group I to the Fifth Assessment Report of the Intergovernmental Panel on Climate Change, edited by: Stocker, T. F., Qin, D., Plattner, G.-K., Tignor, M., Allen, S. K., Boschung, J., Nauels, A., Xia, Y., Bex, V., and Midgley, P. M., Cambridge University Press, Cambridge, UK and New York, NY, USA, 2013.

Jones, A., Haywood, J., Boucher, O., Kravitz, B., and Robock, A.: Geoengineering by stratospheric $\mathrm{SO}_{2}$ injection: results from the Met Office HadGEM2 climate model and comparison with the Goddard Institute for Space Studies ModelE, Atmos. Chem. Phys., 10, 5999-6006, doi:10.5194/acp-10-5999-2010, 2010.

Kaplan, A., Cane, M., Kushnir, Y., Clement, A., Blumenthal, M., and Rajagopalan, B.: Analyses of global sea surface temperature 1856-1991, J. Geophys. Res., 103, 18567-18589, 1998.

Kirtman, B. P. and Schopf, P. S.: Decadal variability in ENSO predictability and prediction, J. Climate, 11, 2804-2822, 1998.

Kravitz, B., Robock, A., Boucher, O., Schmidt, H., Taylor, K. E., Stenchikov, G., and Schulz, M.: The Geoengineering Model Intercomparison Project (GeoMIP), Atmos. Sci. Lett., 12, 162167,2011

Kravitz, B., Robock, A., Tilmes, S., Boucher, O., English, J. M., Irvine, P. J., Jones, A., Lawrence, M. G., MacCracken, M., Muri, H., Moore, J. C., Niemeier, U., Phipps, S. J., Sillmann, J., Storelvmo, T., Wang, H., and Watanabe, S.: The Geoengineering Model Intercomparison Project Phase 6 (GeoMIP6): simulation design and preliminary results, Geosci. Model Dev. Discuss., 8, 4697-4736, doi:10.5194/gmdd-8-4697-2015, 2015.

Li, J., Xie, S.-P., Cook E. R., Morales, M., Christie, D., Johnson, N., Chen, F., D'Arrigo, R., Fowler, A., Gou, X., and Fang, K.: El Niño modulations over the past seven centuries, Nat. Clim. Change, 3, 822-826, 2013.

Maher, N., McGregor, S., England, M. H., and Gupta, A. S.: Effects of volcanism on tropical variability, Geophys. Res. Lett., 42, 6024-6033, 2015.

Mann, M. E., Cane, M. A., Zebiak, S. E., and Clement, A.: Volcanic and solar forcing of the tropical Pacific over the past 1000 years, J. Climate, 18, 447-456, 2005.
Marcott, S. A., Shakun, J. D., Clark, P. U., and Mix, A. C.: A reconstruction of regional and global temperature for the past 11300 years, Science, 339, 1198-1201, 2013.

McGregor, S., Timmermann, A., England, M. H., Elison Timm, O., and Wittenberg, A. T.: Inferred changes in El Niño-Southern Oscillation variance over the past six centuries, Clim. Past, 9, 22692284, 2013, http://www.clim-past.net/9/2269/2013/.

McPhaden, M. L., Zebiak, S. E., and Glantz, M. H.: ENSO as an integrating concept in earth science, Science, 314, 1739-1745, 2006.

Meinshausen, M., Smith, S. J., Calvin, K., Daniel, J. S., Kainuma, M. L. T., Lamarque, J.-F., Matsumoto, K., Montzka, S. A., Raper, S. C. B., Riahi, K., Thomson, A., Velders, G. J. M., and van Vuuren, D. P. P.: The RCP greenhouse gas concentrations and their extension from 1765 to 2300, Climatic Change, 109, 213-241, doi:10.1007/s10584-011-0156-z, 2011.

Phipps, S. J., Rotstayn, L. D., Gordon, H. B., Roberts, J. L., Hirst, A. C., and Budd, W. F.: The CSIRO Mk3L climate system model version 1.0 - Part 1: Description and evaluation, Geosci. Model Dev., 4, 483-509, doi:10.5194/gmd-4-483-2011, 2011.

Phipps, S. J., Rotstayn, L. D., Gordon, H. B., Roberts, J. L., Hirst, A. C., and Budd, W. F.: The CSIRO Mk3L climate system model version 1.0 - Part 2: Response to external forcings, Geosci. Model Dev., 5, 649-682, doi:10.5194/gmd-5-649-2012, 2012.

Power, S. B. and Smith, I. N.: Weakening of the Walker Circulation and apparent dominance of El Niño both reach record levels, but has ENSO really changed?, Geophys. Res. Lett., 34, L18702, doi:10.1029/2007GL030854, 2007.

Robock, A.: Whither geoengineering?, Science, 320, 1166-1167, 2008.

Robock, A., Marquardt, A., Kravitz, B., and Stenchikov, G.: The benefits, risks, and costs of stratospheric geoengineering, Geophys Res. Lett., 36, L19703, doi:10.1029/2009GL039209, 2009.

Schmidt, G. A., Ruedy, R., Hansen, J. E., Aleinov, I., Bell, N., Bauer, M., Bauer, S., Cairns, B., Canuto, V., Cheng, Y., Del Genio, A., Faluvegi, G., Friend, A. D., Hall, T. M., Hu, Y., Kelley, M., Kiang, N. Y., Koch, D., Lacis, A. A., Lerner, J., Lo, K. K., Miller, R. L., Nazarenko, L., Oinas, V., Perlwitz, J. P., Perlwitz, J., Rind, D., Romanou, A., Russell, G. L., Sato, M., Shindell, D. T., Stone, P. H., Sun, S., Tausnev, N., Thresher, D., and Yao, M. S.: Present-day atmospheric simulations using GISS ModelE: Comparison to in situ, satellite and reanalysis data, J. Climate, 19, 153-192, 2006.

Siegenthaler, U., Stocker, T. F., Monnin, E., Luthi, D., Schwander J., Stauffer, B., Raynaud, D., Barnola, J. M., Fischer, H., MassonDelmotte, V., and Jouzel, J.: Stable carbon cycle-climate relationship during the late Pleistocene, Science, 310, 1313-1317, 2005.

Taylor, K. E., Stouffer, R. J., and Meehl, G. A.: An overview of CMIP5 and the experiment design, B. Am. Meteorol. Soc., 93, 485-498, doi:10.1175/BAMS-D-11-00094.1, 2012.

Tokinaga, H., Xie, S. P., Deser, C., Kosaka, A., and Okumura, Y. M.: Slowdown of the Walker Circulation driven by tropical IndoPacific warming, Nature, 491, 439-443, 2012.

Trenberth, K. E. and Hoar, T. J.: El Niño and climate change, Geophys. Res. Lett., 24, 3057-3060, 1997.

Vecchi, G. A. and Soden, B. J.: Global warming and the weakening of the tropical circulation, J. Climate, 20, 4316-4340, 2007. 
Vecchi, G. A., Soden, B. J., Wittenberg, A. T., Held, I. M., Leetmaa, A., and Harrison, M. J.: Weakening of tropical Pacific atmospheric circulation due to anthropogenic forcing, Nature, 441, 73-76, 2006.

Watanabe, S., Hajima, T., Sudo, K., Nagashima, T., Takemura, T., Okajima, H., Nozawa, T., Kawase, H., Abe, M., Yokohata, T., Ise, T., Sato, H., Kato, E., Takata, K., Emori, S., and Kawamiya, M.: MIROC-ESM 2010: model description and basic results of CMIP5-20c3m experiments, Geosci. Model Dev., 4, 845-872, doi:10.5194/gmd-4-845-2011, 2011.
Yeh, S. W., Ham, Y.-G., and Lee, J.-Y.: Changes in the tropical Pacific SST trend from CMIP3 to CMIP5 and its implication of ENSO, J. Climate, 25, 7764-7771, 2012.

Zebiak, S. E. and Cane, M. L.: A model El Niño/Southern Oscillation, Mon. Weather Rev., 115, 2262-2278, 1987. 